Florida International University

FIU Digital Commons

$10-19-2011$

\title{
A Study of the Relationship Between Educational Placment and the Achievement of Urban Low Socioeconomic Hispanic Middle School Students With and Without Specific Learning Disabilities
}

Lisa A. Barrocas

Florida International University, lisa.barrocas@fiu.edu

DOI: $10.25148 /$ etd.FI11120605

Follow this and additional works at: https://digitalcommons.fiu.edu/etd

\section{Recommended Citation}

Barrocas, Lisa A., "A Study of the Relationship Between Educational Placment and the Achievement of Urban Low Socioeconomic Hispanic Middle School Students With and Without Specific Learning Disabilities" (2011). FIU Electronic Theses and Dissertations. 499.

https://digitalcommons.fiu.edu/etd/499

This work is brought to you for free and open access by the University Graduate School at FIU Digital Commons. It has been accepted for inclusion in FIU Electronic Theses and Dissertations by an authorized administrator of FIU Digital Commons. For more information, please contact dcc@fiu.edu. 


\section{FLORIDA INTERNATIONAL UNIVERSITY}

Miami, Florida

\section{A STUDY OF THE RELATIONSHIP BETWEEN EDUCATIONAL PLACEMENT AND THE ACHIEVEMENT OF URBAN LOW SOCIOECONOMIC HISPANIC MIDDLE SCHOOL STUDENTS WITH AND WITHOUT SPECIFIC LEARNING DISABILITIES}

A dissertation submitted in partial fulfillment of the requirements for the degree of DOCTOR OF EDUCATION

in

EXCEPTIONAL STUDENT EDUCATION

by

Lisa A. Barrocas

2011 
To: Dean Delia C. Garcia

College of Education

This dissertation, written by Lisa A. Barrocas, and entitled A Study of the Relationship between Educational Placement and the Achievement of Urban Low Socioeconomic Hispanic Middle School Students with and without Specific Learning Disabilities, having been approved in respect to style and intellectual content, is referred to you for judgment.

We have read this dissertation and recommend that it be approved.

Patricia Barbetta

$\begin{array}{r}\text { Louis Manfra } \\ \hline \text { Diana Valle Riestra } \\ \hline \text { Elizabeth Cramer, Major Professor }\end{array}$

Date of Defense:

The dissertation of Lisa A. Barrocas is approved.

Dean Delia C. Garcia

College of Education

Dean Lakshmi N. Reddi University Graduate School

Florida International University, 2011 
C Copyright 2011 by Lisa A. Barrocas

All rights reserved. 


\section{DEDICATION}

This dissertation is dedicated to my greatest supporters, my children Taylor and Christopher, for being both delightful distractions from this dissertation and for being my motivation for completing the task itself. My hope is for you to find the value of hard work, persistence, and creativity and that it leads you to find your path and your passion. 


\section{ACKNOWLEDGMENTS}

This dissertation could not have been completed without the encouragement and support of many wonderful people including Dr. Patricia Barbetta and Dr. Elizabeth Cramer for creating the Urban SEALS grant. Without their academic guidance and financial support, this process would not have been possible.

The members of my committee each played a significant role in my achievement and success. I have been extremely fortunate to have Dr. Elizabeth Cramer throughout this journey. To work with someone as patient, supportive, and committed is something I wish for all future doctoral candidates. I would also like to express deep gratitude to Dr. Patricia Barbetta for her guidance and support; as well as Dr. Diana Valle-Riestra and Dr. Louis Manfra for providing helpful advice and support along the way. My most sincere appreciation also goes to Dr. Isadore Newman for his support and flexibility.

I could not have made it through the ups and downs of my doctoral studies without my cohort. I will treasure the friendships that were created during this educational pilgrimage.

In addition to my colleagues, I would like to acknowledge my friends and family that supported me throughout this endeavor. A special thank you goes to my parents for their faith in me and for instilling in me the strong work ethic that I have. 
ABSTRACT OF THE DISSERTATION

A STUDY OF THE RELATIONSHIP BETWEEN EDUCATIONAL PLACEMENT

AND THE ACHIEVEMENT OF URBAN LOW SOCIOECONOMIC HISPANIC

MIDDLE SCHOOL STUDENTS WITH AND WITHOUT SPECIFIC LEARNING

DISABILITIES

by

Lisa A. Barrocas

Florida International University, 2011

Miami, Florida

Professor Elizabeth Cramer, Major Professor

Public schools traditionally have been held accountable for educating the majority of the nation's school children, and through the years, these schools have been evaluated in a variety of ways. Currently, evaluation measures for accountability purposes consist solely of standardized test scores. In the past, only test scores of general education students were analyzed. Laws governing the education of students with disabilities, however, have extended accountability measures not only to include those students, but to report their scores in a disaggregated form (No Child Left Behind Act, 2001). The recent emphasis on accountability and compliance has resulted in the need for schools to carefully examine how programs, services, and policies impact student achievement (Bowers \& Figgers, 2003).

Standard-based school reform and accountability systems have raised expectations about student learning outcomes for all students, including those with disabilities and minority students. Yet, overall, racial/ethnic minority students are 
performing well below their White non-Hispanic peers in most academic areas.

Additionally, with respect to special education, there exists an enduring problem of disproportionate representation of racial/ethnic minority students (National Research Council, 2000).

This study examined classroom placement (inclusive versus non-inclusive) relative to academic performance of urban, low socioeconomic Hispanic students with and without disabilities in secondary content area classrooms. A mixed method research design was used to investigate this important issue using data from a local school district and results from field observations. The study compared performance levels of four middle school Hispanic student subgroups (students with disabilities in inclusive settings, students without disabilities in inclusive settings, students with disabilities in resource settings, and student without disabilities in general education settings) each in their respective placements for two consecutive years, exploring existing practices within authentic settings.

Significant differences were found in the relationship of educational placement and achievement between grade level and disability in the areas of math and reading. Additionally, clear and important differences were observed in student-teacher interactions. Recommendations for further researchers and stakeholders include soliciting responses from teams at the schools composed of general education and special education teachers, administrative personnel, and students as well as broadening the study across grade levels and exceptionalities. 


\section{TABLE OF CONTENTS}

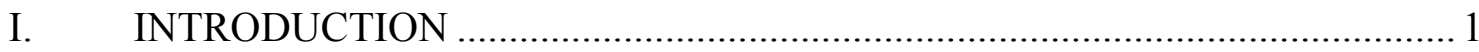

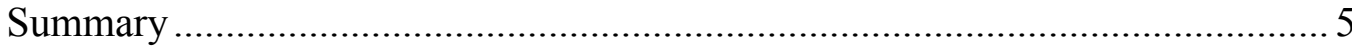

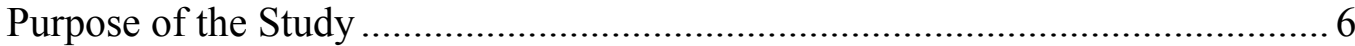

Statement of the Problem................................................................................... 8

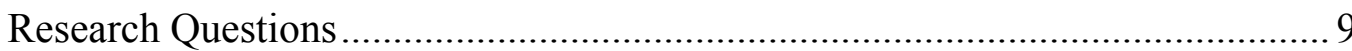

Delimitations......................................................... 10

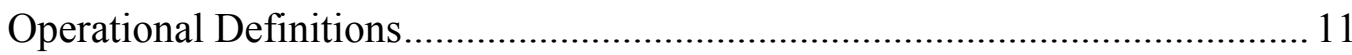

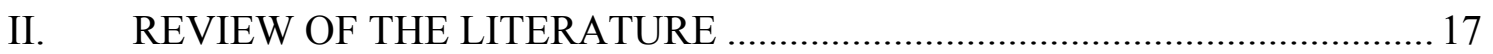

Impact of Inclusion on Academic Achievement and Student Engagement........ 19

High-Stakes, Standardized Testing................................................................. 27

Minority Students and High-Stakes Testing ................................................30

Students with Disabilities and High-Stakes Testing .........................................33

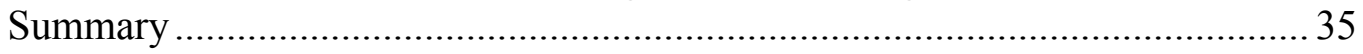

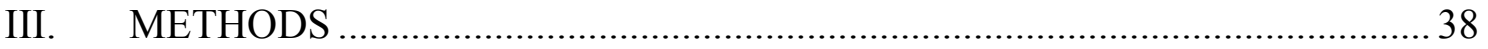

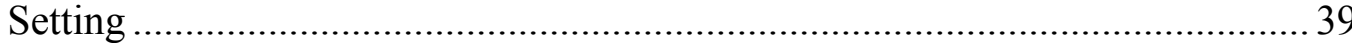

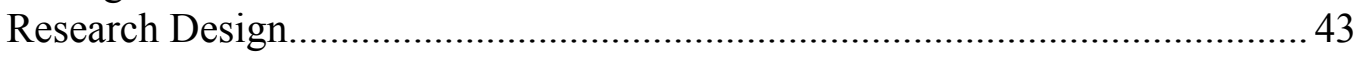

Strand I

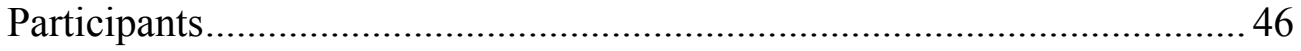

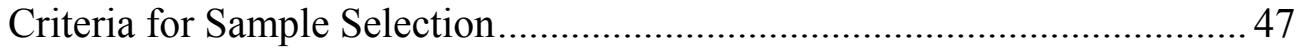

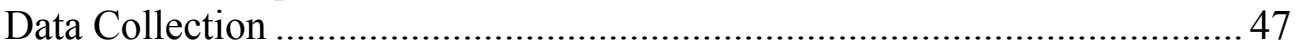

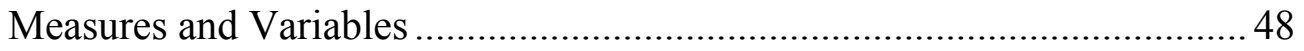

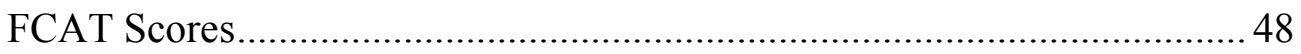

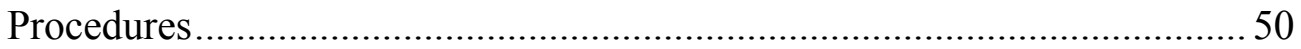

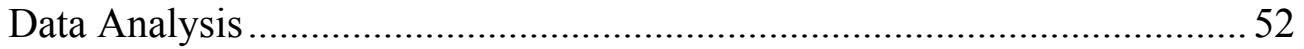

Strand II

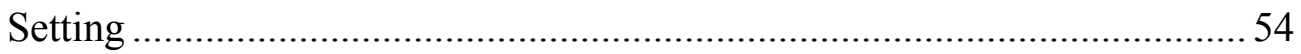

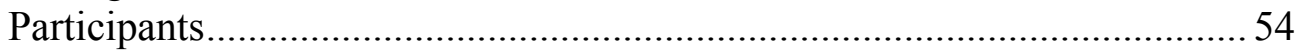

Criteria for Sample Selection............................................................... 57

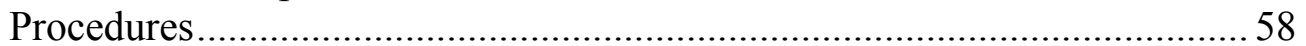

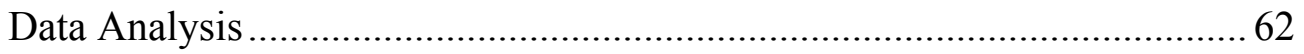

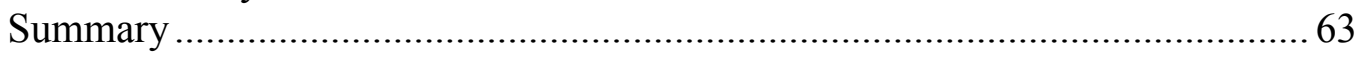

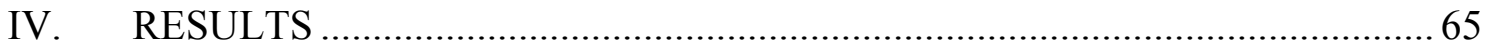

Strand I

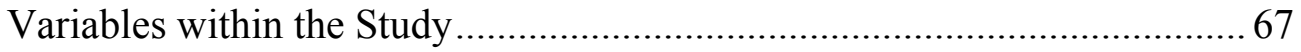

Table Summaries and Related Analyses of Findings .................................. 71 Strand II

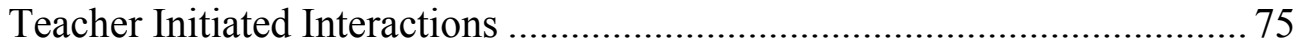

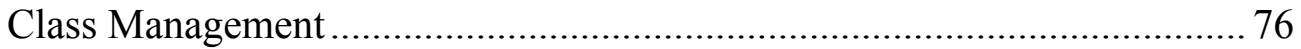




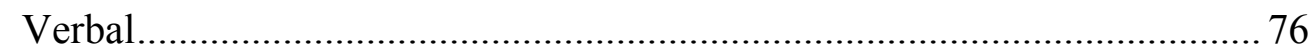

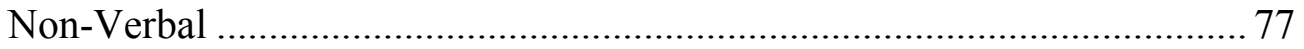

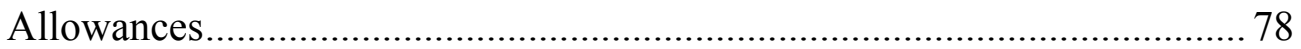

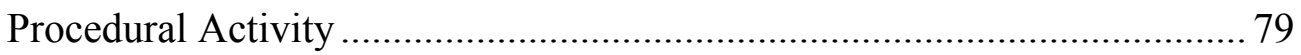

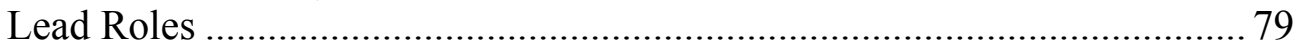

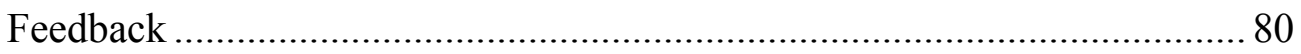

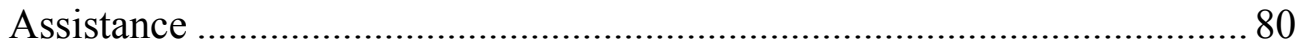

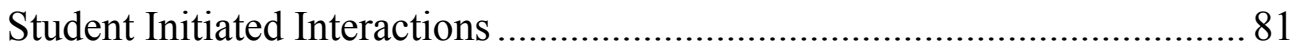

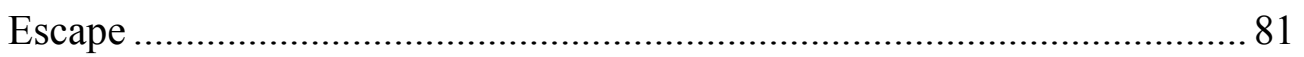

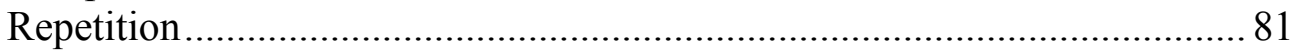

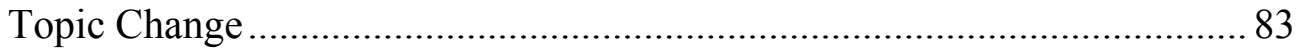

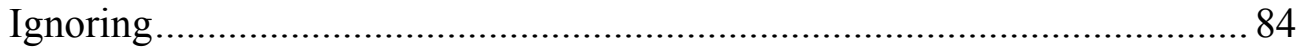

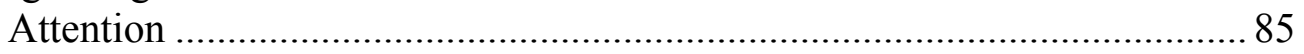

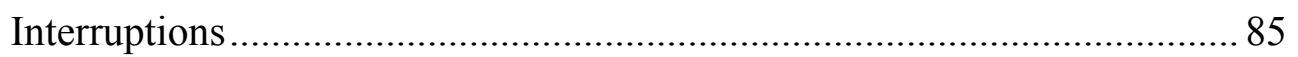

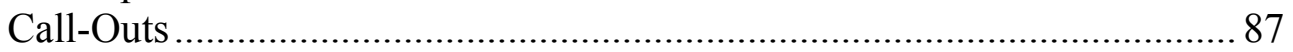

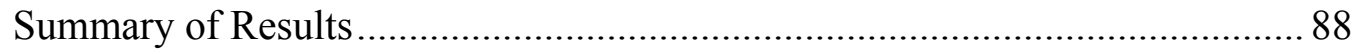

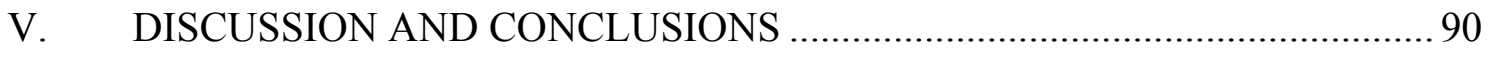

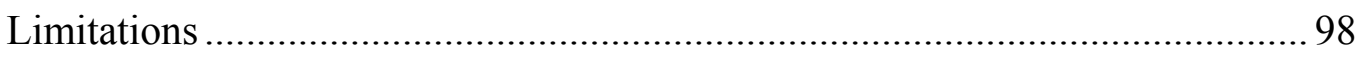

Recommendations for Future Research .................................................... 99

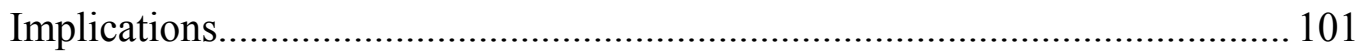

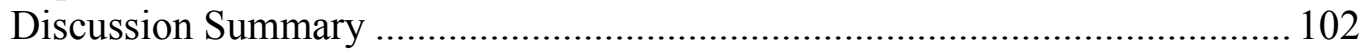

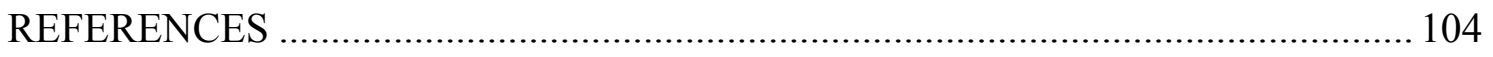

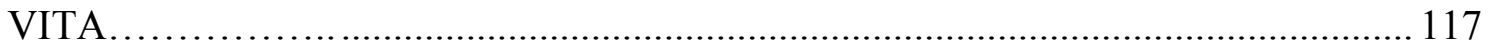




\section{LIST OF TABLES}

TABLE

PAGE

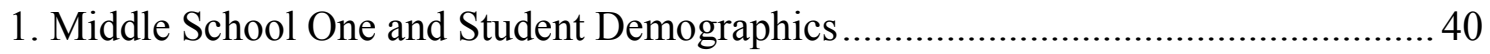

2. Student and Exceptional Program Information............................................... 40

3. Middle School Two Student Demographics ..................................................... 41

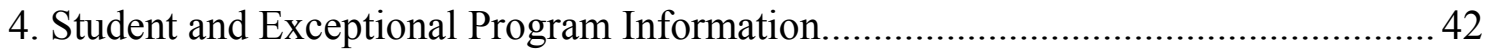

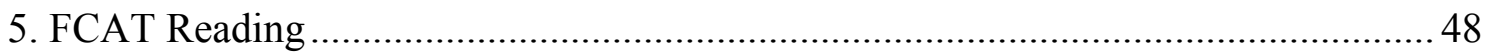

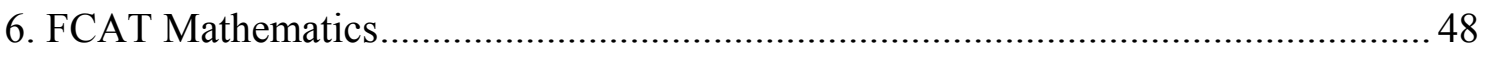

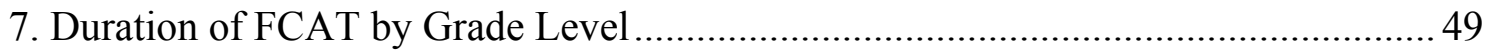

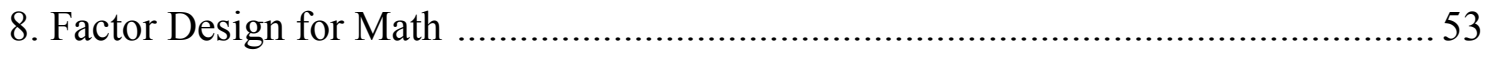

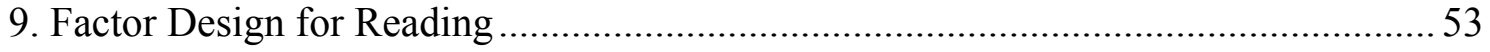

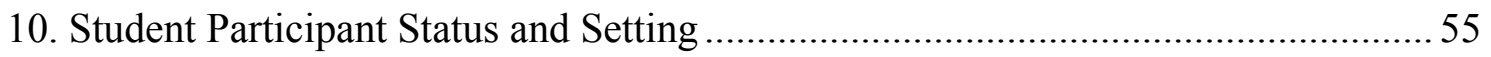

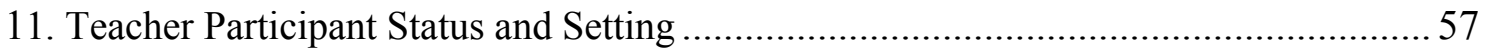

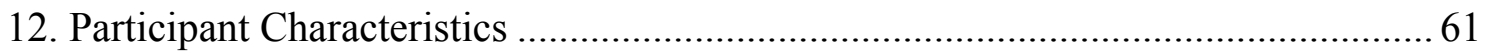

13. Detailed Process of Data Analysis for Strand II ............................................ 63

14. Descriptive Statistics for Math Developmental Scores ....................................... 68

15. Descriptive Statistics for Reading Developmental Scores.....................................69

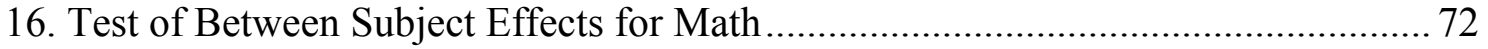

17. Test of Between Subject Effects for Reading .............................................. 72 


\section{CHAPTER I}

\section{INTRODUCTION}

Staggering performance gaps for students with disabilities have suggested a need for reconsideration of special education practices (Artiles, 2003; Lipsky, 2005). According to Bielinski and Ysseldyke (2000) in a nationwide study, there was a 37\% difference in pass rates between students with disabilities and students without disabilities on statewide reading and mathematics assessments. These discrepancies are also apparent in the State of Florida. Data from the 2006-2007 Florida Comprehensive Achievement Test (FCAT) place students with disabilities performing 32 points lower in reading and 39 points lower in mathematics than their non-disabled peers (Florida Department of Education, 2007). Data trends continue with the most recent data, 20072008, indicating students with disabilities performed 37 points lower in reading and 38 points lower in mathematics than their non-disabled peers (Florida Department of Education, 2008). Schools must assess how educational services are being delivered as well as student placement decisions in order to understand achievement trends for students with disabilities.

Varieties of educational service models, governed by laws, have been developed and have guided special education practices over the last five decades in special education (Andrews et al. 2000). The history of special education suggests that the continuum of exclusionary practices will not be useful in an era of educational reform due to an ongoing lack of improved performance (Rea, McLaughlin, \& Walther-Thomas, 2002; Strieker \& Logan, 2001; Wallace, Anderson, Bartholomay, \& Hupp, 2002). 
In 1975, the Education of all Handicapped Children Act (later renamed the Individual with Disabilities Education Act) introduced the concept of instructing students in the least restrictive environment (LRE), mandating that students with disabilities (SWD) be educated, to the maximum extent possible, alongside the general student population. LRE refers to the legal practice where students with disabilities are to be educated as close to the general education environment as is appropriate on a student-bystudent basis with support (Wehmeyer, Lattin, \& Agran, 2001).

In 1983, the National Commission on Excellence in Education declared that the nation was at risk due to the "rising tide of mediocrity" in public education (National Commission on Excellence in Education, 1983, p.1). The report, entitled A Nation at Risk, cited a steady decline in student performance on standardized assessments as well as a lack of basic skills in the areas of reading, mathematics, and writing. Although students with disabilities were not specifically mentioned in A Nation at Risk, special education programs were criticized for an unnecessarily different curriculum from general education classrooms, which oftentimes included lower standards and objectives, despite reform movements.

The Individuals with Disabilities Education Act Amendments (IDEA) of 1997 (PL105-17), provided one of the strongest mandates for the participation of students with disabilities in reform efforts by requiring state education agencies to establish performance goals for students with disabilities that were consistent with the goals and standards for students without disabilities. Further, the provisions of IDEA 1997 required the inclusion of SWD in statewide assessments and accountability systems thereby 
incorporating required performance outcomes of students with disabilities into law (National Association of State Directors of Special Education [NASDSE], 2002).

Reforms in the education of students with disabilities were further expanded in the reauthorization of the Elementary and Secondary Education Act of 2001, better known as the No Child Left Behind Act of 2001 (NCLB). NCLB made schools accountable for student participation on standardized tests by requiring each state to develop strong academic standards that describe what all students should know in mathematics, reading, and science.

Lack of satisfactory academic performance by students with disabilities, combined with growing demands for social equity, has prompted a reconsideration of delivery models in education. Although, research has suggested that access to the general education curriculum through inclusive programs has several potential educational and social benefits for students with disabilities as well as their non-disabled peers (Rea, McLaughlin, \& Walther-Thomas, 2002; Saint-Laurent et al., 1998), lower academic achievement among students with disabilities and minority students persists as measured by performance on state tests.

Researchers (i.e., Kao \& Thompson, 2003; Scheurich, Skrla, \& Johnson, 2000) have noted a link between poor school achievement among SWD and higher rates of school dropout, higher levels of problem behaviors, and lower socioeconomic status in adulthood. Additionally, it should be noted that Hispanics are among the fastest growing racial/ethnic group of the population (LeCroy \& Krysik, 2008). Bielinski and Ysseldyke (2000) noted that Hispanic students continue to achieve well below White students in most subject areas and at virtually all grade levels (Barton, 2001). Hispanic student 
subgroups scored 26 points lower in reading and 32 points lower in mathematics than their White peers on formal assessments (U.S. Department of Education, Reading, 2007; U.S. Department of Education, Mathematics, 2007). In the State of Florida, racial/ethical minority students performed 162 points below their White peers in reading and 132 points below their White peers in mathematics in the 2008-2009 state assessment (Florida Department of Education, 2008).

As a result, efforts to strengthen public education for all students, particularly minority students and SWD, have been unfolding throughout the United States with movements catered toward holding schools and systems accountable for student progress in various educational settings (Knowles \& Knowles, 2001; Kochar, West, \& Taymans, 2000; Mastropieri \& Scruggs, 2004). This call for greater educational accountability and compliance can be traced to the wider economic, political, and social contexts of which schools are a part (Leithwood \& Earl, 2000).

Gullant and Rutter (2000) define accountability as the decisions that are made and the actions that are taken as a result of the performance shown by assessment. The importance of academic success and fiscal stability of schools and school districts is not debatable (Paulen, Kallio, \& Stockard, 2001); nor is the renewed interest and focus that has been placed on guaranteeing that every student has access to free and appropriate learning opportunities (Lashway, 2001; McNeil, 2000; Wellstone, 2000). What is debatable are the educational delivery models currently being used. The latter is a result of a lack of satisfactory academic performance by SWD and minority students combined with growing demands for social equity and civil rights. The lack of academic performance has led to increasing identification of students requiring services, and 
ballooning costs of special education, specifically in resource room models (Kavale \& Fornes, 2000).

It is vital to understand the impact of culture on academic achievement and student placement within school programs, especially when recent trends reveal that SWD are increasingly educated in general education classrooms, while the number receiving instruction in resource rooms or separate classes has decreased substantially (Fore, Hagan-Burke, Burke, Boon, \& Smith, 2008; Holloway, 2001). As per the National Center for Educational Statistics (NCES; 2009), 95.9\% of SWD were served in general school buildings in 2005; of those students, $54.2 \%$ of students were served outside of the general classroom for less than $21 \%$ of the school day. An increase in the percentage of SWDs served in the general education can be seen when these 2009 data are compare to 1990 with $94.3 \%$ of SWD were served in general school buildings with $33.1 \%$ of students served outside of the general classroom for less than $21 \%$ of the school day (NCES, 2009). Currently, Florida reports that 51\% of SWD are educated in the general education classroom for at least $80 \%$ of the school day which is $1.1 \%$ higher than the national average (Office of Special Education and Rehabilitative Services [OSERS], 2007). Despite the increase in the inclusion of SWD within the general classroom setting, there is limited research, particularly at the secondary level, to suggest where these students achieve more academically.

\section{Summary}

Trends in special education indicate a shift toward including SWD in the general education classroom with their non-disabled peers (Giacobbe, Livers, Thayer-Smith, \& Walther-Thomas, 2001; Kavale \& Fornes, 2000). This trend toward inclusion is 
consistent with the LRE provisions of IDEA. While varying philosophical perspectives and limited data continue to fuel the placement debate, the overriding question remains whether inclusion is the best method for assisting all students in making Annual Yearly Progress (AYP), thereby, helping schools to meet accountability requirements.

Additionally, schools are now serving students who traverse cultural and linguistic borders. Unfortunately, it is a fact that a disproportionate number of minority students are placed in special education (National Research Council [NRC], 2002; Artiles, Rueda, Salazar, \& Higareda, 2005). As per Artiles, Trent, and Palmer (2004), placement in special education is related to the level of analysis (national, state, district, school), percentage of minority enrollment, and district size. With Hispanics being among the fastest growing racial/ethnic group of the population (LeCroy \& Krysik, 2008), and as more SWD are included in general education classes, it is critical to examine the relationship between models of special education service delivery and academic outcomes for students with and without disabilities of this subgroup. Based on the fact that empirical data describing trends in student achievement are extremely limited, this study looked at the relationships between program deliverance placement, student behaviors related to academic achievement, and learning changes in the annual state assessment administered in the State of Florida from the 2008-2009 to 2009-2010 school year.

\section{Purpose of the Study}

The purpose of this study was to examine classroom placement (inclusive versus non-inclusive) relative to the academic performance of Hispanic students with disabilities and their non-disabled peers in secondary content area classrooms. The study compared 
performance levels of four middle school student subgroups (students with disabilities in inclusive settings, students without disabilities in inclusive settings, students with disabilities in resource settings, and student without disabilities in general education settings) each in their respective placements for two consecutive years, exploring existing practices within authentic settings. Students were selected based on similar socioeconomic status, ethnicity, disability status, school attendance, and language dominance.

Faced with accountability mandates, school leaders must identify structures and practices that fail to promote students' performance and growth and replace them with systems that will benefit all students. The examination of an approach to special education service delivery that holds promise for improving the performance of SWD has clear significance for all. Of the many issues related to the integration or inclusion of students with disabilities into the general education classrooms, there is none more important than the effects of placement on students' learning (Fore, Hagan-Burke, Burke, Boon, \& Smith, 2008). The effects of inclusion, in respect to student placement, specifically co-teaching versus a non-inclusive setting (resource room or general education setting), of students with and without disabilities on academic achievement could be of assistance to administrators and others in evaluative positions to maximize efficiency and value. Information gained from this study may be useful in planning and implementing programs for students with specific learning disabilities in other school districts, resulting in higher academic achievement scores for minority students with and without disabilities. 


\section{Statement of the Problem}

Standard-based school reform and accountability systems have raised expectations about learning outcomes for both general and special education students. As more SWD are included in general education classrooms, and with the emphasis placed by recent legislative reforms on the outcomes of special education students, it is critical to examine the relationship between models of special education service delivery (placement), specifically inclusion in general education and resource rooms (Giacobbe et. al, 2001; Kavale \& Fornes, 2000).

Students receive instruction based on the LRE mandate and on the standard curriculum approved by the state and local education agency. Henceforth, learning outcomes are now to be gauged across two measures for special education students: the student's Individual Educational Plan (IEP) and standards' benchmarks as measured by AYP on state formal assessments in the areas of mathematics, science, and reading.

Today, as schools face the challenge to fulfill their responsibility to all students, the achievement of diverse populations, including SWD, poses a significant dilemma as these students continue to experience significant lags in performance. As increasing numbers of students emerge with diverse needs in general education classrooms, educators are searching for increasingly effective ways to meet the needs of these students (Murawski \& Swanson, 2001) while simultaneously meeting the needs of their general education counterparts. Kirkpatrick-Johnson, Crosnoe, and Elder (2001)

commented that even within a general education setting, racial and ethical minority youth spend significantly less time directly engaged in academic learning than do their White counterparts. Subsequently, professionals continue to have many questions about how to 
provide an appropriate educational program for these minority SWD that will enable them to master the general education curriculum (Andrews et al., 2000).

Unfortunately, little research has critically examined the impact of placement on academic achievement (McDonnell et al., 2003), particularly for Hispanic middle school students with specific learning disabilities (SLD). The limited research that does exist focuses largely on White, non-Hispanic elementary students with disabilities. Nor has current research discovered adequate answers to the question as to which type of educational placement is best for these students' development due to factors such as: lack of random assignment of student groups, lack of comparable control group or groups, and questions regarding whether the placement setting or the quality of teaching within the setting is the critical factor to study. Therefore, due to limited research, further investigation was warranted concerning the impact of different educational settings on the academic achievement of minority students with and without disabilities (Giacobbe, et.al, 2001; Kavale \& Forness, 2000).

\section{Research Questions}

This study sought to: (a) identify whether educational placement affects student performance and (b) investigate which observable student interactions with the teacher(s) within the classroom setting are related to academic achievement and are present within various settings. The following research questions were addressed:

1. Does placement (inclusive versus non-inclusive classrooms) affect achievement change for urban low socio-economic Hispanic middle school students with and without specific learning disabilities in reading and math? 
2. What interactive behaviors related to academic achievement are observable between student and teacher(s) within different educational placements for urban low-socio-economic Hispanic middle school students with and without specific learning disabilities?

A quantitative approach for this study was utilized for Research Question 1 in order to provide an objective statistical summary of the effects of inclusion on the academic achievement of students with disability and non-disabled students identified for the study. A qualitative approach was used for Research Question 2 to try to gain more in-depth information about specific behaviors that occurred in each setting that may explain any differences in learning gains for SWD and non-disabled students.

\section{Delimitations}

The population was limited to students in similar settings and learning conditions in an urban school district. Specifically, this study was restricted to two "A-rated" middle schools and a total of four middle school teachers: two general education teachers who co-taught an inclusion class and a general education class, and two special education teachers who co-taught an inclusion class and a resource class in reading or mathematics. The referred "A" rating is a system based on FCAT results, assigning a letter grade (A-F) to each participating public school in the state of Florida. As per the Florida Department of Education, a rating of " $\mathrm{A}$ " indicates that the school met adequate progress of their lowest students in reading and mathematics (Data Analysis for School Improvement, 2009). As the school ratings were high, the findings may not be applicable to schools not meeting adequate progress. 
The sample of each of the student groups compared was obtained from a district where inclusion has been a major initiative specifically within the primary levels. As such, students with disabilities are included at a higher rate in elementary, and inclusion numbers start to decrease in secondary settings (U.S.DOE OSERS, 2005). The variation in inclusion rates may affect the results with respect to variation in teaching models and ability to generalize.

\section{Operational Definitions}

For the purpose of this study, the following terms are defined as follows:

\section{Accountability}

A system of policies and procedures that provide rewards and sanctions to students, school divisions, schools, and school staff as a consequence of student performance on state assessments (Nolet \& McLaughlin, 2000).

\section{Achievement Changes}

Refers to the monitoring of how much students learn from one year to the next. Since FCAT reading and math exams are given in grades $3-10$, it is possible to monitor learning changes in these content areas.

\section{Adequate Yearly Progress (AYP)}

A requirement of all public schools under NCLB to meet student performance targets or annual measurable objectives defined by the state within a specified timeframe (U.S. Department of Education, Stronger Accountability, 2003). In Florida, AYP requires a 95\% participation rate in the state assessment programs for all students in the school and meeting performance targets in mathematics, reading and science. AYP applies to all students, as well as students in four subgroups: students with disabilities; students with 
limited English proficiency; students who are economically disadvantaged; and students from racial/ethnic minority groups.

\section{Co-Teaching}

Classroom environment where a general education teacher and a special education teacher provide instruction together to a heterogeneous class in terms of student disabilities or lack thereof (Friend \& Cook, 2003).

\section{Engagement}

Student engagement can be defined as the level of participation and intrinsic interest a student shows in school (Newmann, 1992) implying behaviors such as effort and attention and attitudes such as motivation (Johnson, Crosnoe, \& Elder, 2001).

\section{English for Speakers of Other Languages (ESOL)}

English language learners; students whose first language is not English.

\section{Florida Comprehensive Assessment Test (FCAT)}

A standardized test used in Florida primary and secondary schools to assess students' attainment of reading, writing, math, and science skills required under Florida education standards.

\section{General Curriculum}

Refers to the same curriculum as that of non-disabled children (Federal Register, 1999, p. 12592).

\section{General Education Teacher (General Educator)}

Educator who provides instruction to students within the general education curriculum (CEC, 2008). 


\section{Hispanic}

A person of Mexican, Puerto Rican, Cuban, Central or South American or other Spanish culture or origin (United States Census Bureau and the Federal Office of Management and Budget, 2009)

Individuals with Disabilities Education Improvement Act of 2004 (IDEIA)

On December 3, 2004, President George W. Bush signed into law the Individuals with Disabilities Educational Improvement Act (P.L. 108-446), the most recent reauthorization to IDEA. Highly qualified provisions in IDEIA of 2004 were aligned with NCLB of 2001.

\section{Inclusion}

Bateman and Bateman (2002) described inclusion as students with disabilities being meaningful participants in general education classrooms. The National Center on Accessing the General Curriculum (2002) defines inclusion as students with disabilities having membership in general education classrooms with age-appropriate peers where they have individualized and relevant learning objectives, and are provided with the instructional support to access the curriculum of the classroom. Although a variety of definitions have been used in the literature, it should be noted that each definition of inclusion suggested a common theme in which students enrolled in special education programs are served in the general education classrooms for all or part of the school day (Pearpoint, Firest, \& Snow, 1992). For the purpose of this study, inclusive classrooms have been defined as educational settings where a general education and a special education teacher co-teach the entire school day. 


\section{Interactive Behaviors}

As per Hertz-Lazarowitz and Miller (1992), interactive behaviors are the actions or reactions of a person in response to external or internal stimuli as they constitute a means of evaluation by others.

\section{Learning Disability}

A disorder in one or more basic psychological processes involved in understanding or in using language, spoken or written that may manifest itself in an imperfect ability to listen, speak read, write, spell, or to do mathematical calculations (IDEA).

\section{Least Restrictive Environment (LRE)}

Requires states to have policies and procedures for ensuring that, to the maximum extent appropriate, children with disabilities are educated with children who are not disabled, and that special classes, separate schooling, or other removal of children with disabilities from the regular educational environment occurs only if the nature or severity of the disability is such that education in regular classes with the use of supplementary aids and services cannot be achieved satisfactorily.

\section{Middle School}

Middle schools are schools that house sixth grade through eighth grade students.

\section{Minority Students}

A minority student is one who is either: African American/Black, a person having origins in any of the Black racial groups in Africa; Hispanic American, a person of Spanish culture. 


\section{No Child Left Behind of 2001 (NCLB)}

Reauthorization of the Elementary and Secondary Education Act implemented to close the achievement gap through accountability measures, flexibility and choice.

\section{Resource Room}

Classrooms where students were segregated from their non-disabled peers for most or all of the school day (Smith, Polloway, Patton, \& Dowdy, 1998). For purposes of this study, a resource room was a classroom taught exclusively by a special education teacher.

\section{Socioeconomic Status}

Students in the study identified as socioeconomic status (SES) were students eligible for free or reduced meals based on a sliding scale of the total household and the household size (Food and Nutrition, 2007).

\section{Special Education Teacher (Special Educator)}

Educator who provides specially designed instruction to students with disabilities (SWD; CEC, 2008)

\section{Standards}

General statements of what students should know or be able to do as a result of their public school education as measured by each state.

\section{Specific Learning Disabled (SLD)}

Difficulties with psychological or information processing in students with normal intelligence, that often result in significant problems with learning basic skills in some academic areas (State of Florida, 2000). 


\section{Student with Disability (SWD)}

A student who, by a series of tests, has been identified as having a disability that impedes his/her educational progress. These students receive services and support from their school's special education program designed to enable them to be educated to their full potential (Smith et al., 1998).

\section{Value-added Assessment}

For purposes of this study, value-added assessment is defined as a method of analyzing student test data to ascertain students' growth in learning by comparing students' current level to their past level (American Educational Research Association, 2004). 


\section{CHAPTER II}

\section{REVIEW OF THE LITERATURE}

Public schools have traditionally been held accountable for educating the majority of the nation's school children. Through the years, schools have been evaluated in a variety of ways. The current emphasis on accountability has resulted in the need for schools to carefully examine how programs, services, and policies impact student achievement, including the cost of programs versus student outcomes (Bowers \& Figgers, 2003), the best practices for inclusion (Kovacs, 2006: Young, 2004), ways to enhance student success in inclusion (Lowery, 2003: Storm, 2006), private versus public schools and inclusive success (Finegan, 2005), and details in student outcomes in an inclusive setting (Hull, 2005). Student outcomes are a critical aspect in the study of inclusion since they are the determining factor of inclusion's success as measured through accountability requirements. As such, the impact that inclusion of students with disabilities in general education classrooms has on academic progress must be at the forefront of evaluation among professional educators.

The concept of inclusion revolves around providing individualized instruction and support services for students with disabilities within the context of a general education classroom. Therefore, the debate resulting from the evaluation of programs and policies surrounding inclusion practices centers around where the disabled student should be taught for the benefit of all students rather than how or what is being taught.

In Chapter 1, research questions were asked regarding the effectiveness of educational settings and instructional practices in student performance levels as measured by AYP through an analysis of changes in developmental scale scores on formal state 
assessments, indicating learning changes made from one year to the next in the areas of reading and mathematics. These questions call for analyzing student performance on the 2009 state assessment data as well as data collected through observations of student behaviors related to academic success for students with disabilities and general education students being serviced within an inclusive and resource setting.

In this chapter, the empirical and theoretical issues pertaining to educational settings and academic achievement in high-stakes, standardized tests as well as student behaviors observed in the respective settings, for SWD and non-disabled peers were explored to examine factors such as least restrictive environment and student academic success. This chapter provides a frame of reference for this study exploring a discussion of the impact on the effect of middle school inclusion on special education and general education students' annual learning changes on formalized state assessments as well as levels of students' engagement within classroom settings. Student engagement can be defined as the level of participation and intrinsic interest a student shows in school (Newmann, 1992) implying behaviors such as effort and attention and attitudes such as motivation (Johnson, Crosnoe, \& Elder, 2001). Emphasis is placed on minority students due to the fast growing minority population within the United States. In 2005, as per the National Council of Educational Services, minorities made up 33\% of the U.S. population. Hispanics were the largest minority group, representing $14 \%$ of the population. In Florida, Hispanics comprise 19\% of the population. 


\section{Impact of Inclusion on Academic Achievement and Student Engagement}

Research on inclusion of students with disabilities in the general education setting and the impact inclusion has on the academic achievement for both the disabled and nondisabled student has led to inconclusive results. Erickson (2000) analyzed the academic achievement of 134 general education middle school students in grades 5 and 8 served within inclusive settings versus non-inclusive settings to see if there was a significant difference in achievement test scores, specifically on reading and math subtests on the California Achievement Test, Fifth Edition. Results indicated that inclusive settings yielded no significance difference between achievement levels.

Yair (2000) conducted a study to investigate whether classroom opportunities affect students' engagement and their learning outcomes. Yair utilized the Experience Sampling Method (ESM). ESM is a research methodology which asks participants to stop at certain intervals and make notes of their experiences. Eight hundred and sixty-five students from 33 schools across the nation were sampled, including students in inclusive settings. Students were randomly selected from 13 high schools, five K-6 schools, three K-8 schools, and 12 middle schools. Later, students were stratified by gender, race/ethnicity, ability level, and classroom setting, including inclusion. They were given digital wristwatches that were programmed to emit signals eight times a day for one week. At the signal, students were to answer a short questionnaire about their experiences concerning the activity they were engaged in, and their thoughts and mood. Yair found that race is a strong predictor of engagement. The Asian and White students were reported to be the most engaged (56.5\% and 55.5\% respectively), and the Hispanic and African-American students had the highest rates of alienation from instruction $(50 \%$ and 
$50.6 \%$ respectively were alienated) as per the study regardless of class setting. Yair also found that at-risk status, including SWD, was also correlated with engagement and alienation from instruction. Students with disabilities were less engaged in academic classes by a $5.4 \%$ statistical difference.

In 2001, Dowson and McInerney studied 86 middle students in six schools (two elementary and four secondary schools) utilizing interviews and observations. Results concurred with similar studies conducted by Hancock and Betts (2002) and Lumsden (1994) that engaged students learn more and retain more than students who are not engaged regardless of academic setting. In 2002, Kirsch found a direct link between levels of engagement and achievement in reading and mathematics, but not necessarily among race or disability.

Huber, Rosenfeld, and Fiorello (2001) studied the effect that inclusion has on the achievement scores of general education students. Achievement scores for 477 general education students from grades 1 through 5 were examined over a three-year period. Comparisons were made among different classrooms on achievement that included measures in math and reading on the Metropolitan Achievement Test-Sixth Edition and the Stanford Achievement Test-Eighth Edition. Results across grade levels and settings showed that general education students with lower academic skills appeared to benefit academically, while higher achieving students' test scores dropped.

Rea, McLaughlin, and Thomas (2002) studied two groups of middle school students in special education (36 who received special education services through an inclusive support model and 22 who received special education services through a resource model). The independent variables were the educational setting (inclusive or 
resource). Dependent variables included academic achievement, behavior, and school attendance. (Behavior had been previously measured in a study by Daniel and King in 1997, finding a negative impact on the behavior of general education students within inclusive settings.) Measures of academic achievement included final course grades in the $8^{\text {th }}$ grade content areas and standard scores on reading, mathematics, science, and social studies subtests on the Iowa Test of Basic Skills (ITBS).

Results from that study demonstrated that students served in inclusive settings earned significantly higher grades in all four content areas of instruction (math, science, language arts, and social studies) with $91.7 \%$ of students in inclusive settings earning a "C" or higher in language arts compared to $63.6 \%$ of students in resource settings; $86.1 \%$ earning a " $\mathrm{C}$ " or higher in mathematics compared to $72.7 \%$ in resource settings; $88.9 \%$ of students in inclusive settings earning a "C" or higher in science compared to $59.1 \%$ in resource settings; and $86.1 \%$ of students in inclusive settings in social studies earning a "C" or higher compared to $50 \%$ within a resource settings. In reference to tests results on the ITBS, a significant difference was found between the means of the two groups on the language and mathematics subtests. Study limitations included the setting of the study, a small, suburban school district where two distinctly different service delivery models were in place. Additionally, only one grade level, $8^{\text {th }}$ grade, was analyzed. Students without disabilities were not studied at all.

In another review, Holloway (2001) examined five studies from the late 1990s examining academic achievement and class placement. The focus of all of the studies was on class placement as the independent variables that included academic achievement as a dependent variable. Holloway concluded that a combined model, inclusion and a resource 
setting for some academic instruction, significantly showed academic achievement than in either the inclusion or the resource room only model.

Few studies have investigated the effects of inclusion at the secondary school level. Cawley, Hayden, Cade, and Baker-Kroczynski (2002) reported neutral academic outcomes for the nondisabled students within math, but not so within reading. A limitation to this study is that students' disabilities ranged from mild to moderate in severity.

McDonnell and colleagues (2003) completed an experimental study to evaluate the impact of inclusive educational programs on the achievement of students with disabilities and non-disabled peers. The achievement of 324 students without disabilities who were enrolled in inclusive classroom settings was compared with 221 students without disabilities within a general education classroom setting using a posttest. The students were selected from five elementary schools in four different school districts. Educational achievement was measured utilizing the Utah Core Assessment. The results did not suggest any significant difference among the two groups.

Baldwin (2003) studied a 6th grade mathematics inclusion classroom involving students with learning disabilities to investigate the effects of co-teaching on student engagement. Baldwin sought to find if engaged students participated in activities that led to success within the classroom as a result of placement within a co-taught inclusive classroom versus a resource setting. Baldwin's study indicated no significant difference in student engagement.

Shernoff, Csikszentmihalyi, Schneider, and Shernoff (2003) used Yair's (2000) methods, ESM, to document classroom interactions and academic achievement. Students 
were surveyed multiple times when signaled at randomly occurring intervals by an electronic pager. Shernoff et al. collected data in three waves: 1992-1993 (Year 1), 19941995 (Year 3), and 1996-1997 (Year 5). Twelve research sites across the U.S. were selected for the study. Sites were distributed geographically in level of urbanization, racial and ethnic composition. Students in grades $6,8,10$, and $12(\mathrm{~N}=526)$ were randomly selected. Sixty-four percent of the sample was White, $16 \%$ was AfricanAmerican, 10\% was Hispanic, and 8\% was Asian. Results indicated that Hispanic students had generally lower levels of engagement when the quality of instruction was perceived to be poor. Similar trends were found with African-American students as well as SWD.

Haselden (2004) assessed whether co-teaching had the potential to increase academic achievement for all students. In this quantitative study, achievement results for students in four traditional high school biology classes were analyzed. One class was cotaught, while a second received support from a special educator. The remaining two classes received traditional instruction from one general science teacher. Results indicated no statistically significant differences in passing rates for students in all four settings.

A total of 67 middle school students with disabilities were investigated by Gale (2005) to determine if there were differences in school performance in regard to resource and co-taught placement. Students were matched according to length of time receiving special education services, allowable accommodations, grade-level, goals and objectives in IEPs, chronological age, and intelligence quotients. Results indicated no significant differences on standardized test scores or in attendance among the two groups. This 
finding is significant because it speaks to a considerable range of students. What the study does not indicate is how students without disabilities performed in these same areas.

Another middle school study investigated the effects that co-teaching had on the achievement of students with mild to moderate disabilities in a $7^{\text {th }}$ grade language arts class (Knudson, 2005). Knudson compared students with disabilities using diagnostic tests, teacher-made tests, and class grades. There was no significant difference between the diagnostic pre-and post-tests. Students with disabilities receiving instruction in a cotaught class did not show improvement or regression on high-stakes tests. In fact, findings indicated that students scored basic to below basic level on both assessments; however, students with disabilities did score higher on teacher-made tests and class grades.

Another study focused on secondary English classes taught by general and special educators in four school sites (Murawski, 2006). The purpose of this study was to determine if individual needs of students with disabilities were met in a co-teaching environment. Murawski found no significant differences in academic outcomes for reading and writing assessments for students with learning disabilities in the co-teaching environment as compared to students with disabilities in the mainstream class, in a resource class, or in a general education setting.

In 2007, Kalambouka, Farrell, Dyson, and Kaplan reviewed 26 studies on whether the placement of pupils with disabilities within mainstream schools had an impact on academic and social outcomes for students without disabilities. Overall, the literature review revealed that there were no adverse effects on students without disabilities in 
including students with disabilities. Specifically, the study yielded $58 \%$ of the studies reporting positive effects and $23 \%$ of the studies reporting neutral effects. However, these results may be misleading for older learners as most of the outcomes related to elementary aged students. Those that pertained to secondary schools reported negative outcomes for $81 \%$ of students.

Indiana University School of Education developed a survey (High School Student Survey of Student Engagement; HSSSE) to measure the levels of engagement of high school students. The survey assessed the level of involvement of high school students in activities that were connected with increased levels of learning and development. Three areas of dimensions of student engagement were included on HSSSE: (a) cognitive/intellectual/academic engagement, (b) social/behavioral/participatory engagement, and (c) emotional engagement (Yazzie-Mintz, 2007).

Participating schools ranged in size from 37 students to 3,881 students; the mean student enrollment of participating high schools was 1,010 students. Findings from the study include: White and Asian students report being more engaged than students of other races; students in honors and advanced classes appear to be much more engaged than special education students, with general and vocational students in the middle; students of lower socioeconomic status report being less engaged than students of higher socioeconomic status (Yazzie-Mintz, 2007).

In a study specifically targeting secondary schools, Fore, Hagan-Burke, Burke, Boon, and Smith (2008) studied 57 high school students with specific learning disabilities (SLD) from two suburban high schools in the southeastern United States. Participants in the study received special education services in inclusive and non-inclusive settings in 
grades 9 through 12 representing White, African-American, and Hispanic ethnicities. The only statistically significant difference in academic performance was noted in those students who were placed in a general education reading class versus inclusive or resource settings.

Research studies concerning the inclusion of SWD in the general education setting and the impact inclusion has on the academic achievement for both the disabled and non-disabled student have led to inconclusive results. Of the studies discussed above, the results suggest that SWD, particularly those with SLD, are likely to have better achievement outcomes in more inclusive settings specifically on teacher-made tests and class grades (Rea, et al., 2002; Cawley, et al., 2002; Knudson, 2005). Likewise, studies such as Rea and colleagues (2002) and Cawley and colleagues (2002) provided data indicating that the presence of SWD in general education settings did not negatively impact the academic achievement of students without disabilities as measured by state assessments.

Despite the body of research suggesting that inclusive settings may produce favorable academic gains for SWD, a number of studies suggest that students with SLD fare no better in general education classes than they would in resource settings (Erikson, 2000; Haselden, 2004; Holloway, 2001; Murawski, 2006). Some scholars assert that where services are received is the wrong question to ask (Zigmond, 2003). These scholars focus on student engagement (Baldwin, 2003; Dowson \& McInerney, 2001; Hancock \& Betts, 2002, Kirsch, 2002, Lumsden, 1994; Yair, 2000). Studies conducted by Dowson and colleagues (2001), Hancock and Betts (2002), Lumsden (1994), and Kirsch (2002) all reported that engaged students regardless of setting and/or disability 
performed better academically. Baldwin (2003), Yair (2000), and Shernoff, Csikszentmihalyi, Schneider, and Shernoff (2003) found no significant difference in student engagement in relation to academic performance. In contrast, Kalambouka and colleagues (2007), Yazzie-Mintz (2007) did.

There are few studies examining the impact of co-teaching as a model on student participation and outcomes at the secondary level (Keefe \& Moore, 2004). Yet, largescale studies investigating the impact on student outcomes at this level are necessary in an era when cost effectiveness in terms of student performance achievement drives educational policy. The legislative call for more inclusive programs and an emphasis on accountability systems is a powerful rationale for examining student achievement of secondary students in these settings.

\section{High-Stakes, Standardized Testing}

A major motivation for the use of standardized tests resulted from the launching of Sputnik by the Russians in 1957 (Amrein \& Berliner, 2002). Suddenly the United States was involved in a race for supremacy, not only in the race for space, but also in the education field. The battle began in the nation's classrooms. Many state legislatures rushed to pass legislation that required districts to use standardized tests.

Another driving force behind high-stakes, standardized testing is accountability (Vazquez-Heilig \& Darling-Hammond, 2008). Some educators believe that when schools and students are held accountable, educational output will increase: educators will try harder; schools will adopt more effective methods; and students will learn more, thus producing gains in student achievement (Vazquez-Heilig \& Darling-Hammond, 2008). Others believe that high-stakes testing has constrained schools and teachers in their 
ability to respond to the diverse students in their classes (Fusarelli, 2004; Hargreaves, 2003; Rotberg, 2004) with its one class system of age-graded curriculum, individual seatwork mixed with whole-class teaching, and pencil-and-paper testing (Tyack \& Cuban, 1995) as well as shortchange students with disabilities as teachers feel compelled to cover content leaving less time for teachers to support students who lag behind (McLaughlin, Henderson, \& Rhim, 1998; McLaughlin \& Tilstone, 1999).

Amrein and Berliner (2002) studied test results from 18 states out of the 22 states that had high-stakes testing programs at both the K-8 and high school levels. The sample 18 states were selected based on the consequences associated with their testing policies. The effects of high-stakes tests on learning were measured by examining indicators of student learning, academic accomplishment, and achievement other than the tests associated with high-stakes on the same domains.

These researchers found that high-stakes testing policies did not usually improve the performance of students on the grade 4 or grade 8 National Assessment of Educational Progress (NAEP) math or reading tests. Gains in math and reading were more strongly correlated to who was excluded from the NAEP than to whether or not high-stakes tests were used. Excluded students fell into the general categories of students with disabilities and limited-English proficient students (Amrein \& Berliner, 2002). Flaws within this study included a lack of control group (i.e., identifying states with and those without any form of testing stakes) to analyze NAEP results, as well as exclusion rates of students per states.

In 2003, Amrein and Berliner replicated their 2002 study, reexamining NAEP trends using a control group and analyzing exclusion rates. The authors concluded that 
although states high-stakes tests seemed to outperform those without high-stakes tests on the math NAEP exams, this difference disappears when they controlled for NAEP exclusion rates. Consequently, Amrein and Berliner argued that high-stakes testing does not lead to learning increases, but to greater incentives to exclude low performing students from testing.

Others, like Carnoy and Loeb (2002) report mixed results, after studying the use of high-stakes testing to sanction and reward schools in all fifty states using the NAEP mathematics tests in 1996-2000. Carnoy and Loeb created a 0-5 scale that measured each state's accountability in terms of: (a) how often students were tested (e.g., in which grades), (b) school accountability, (c) repercussions for schools, (d) strength of repercussions for schools, (e) if there is a high school exit test (in 2000), and if so, the grade at which first high school test is given, and (f) the first class that had to pass the test to get their diploma (all information based on data as of 1999-2000).

Carnoy and Loeb (2002) found that states with a higher proportion of minority students and with larger populations are more likely to implement strong accountability. The results indicate a significant relationship between the strength of states' accountability and math achievement gains for students as a whole. When desegregated, however, Carnoy and Loeb found high-stakes testing to be beneficial for certain student groups, such as minority students, and not others, specifically students with disabilities. Students that fell within both categories, minority students and SWD, were categorized as SWD.

In 2006, Nichols, Glass, and Berliner examined the relationship between highstakes testing and student achievement across 25 states using data from the NAEP fourth 
and eighth grade math and reading tests to replicate Carnoy and Loeb's (2002) analysis and to test their conclusion that high-stakes testing is related to achievement gains for minority students. Their study spanned from March 1999 through February 2004. Findings showed an increase in math test results among eighth-grade, African-American students, but no relationship between testing and any other student subgroup or achievement on the NAEP at any grade level or for any ethnic student subgroup. However, there is evidence that students were excluded from NAEP at higher rates during post testing which raises questions for any researcher about the validity of these academic gain scores when using the results of standardized tests.

Initially, the results of standardized testing were most often used to determine what program of studies a student should pursue. Later, the emphasis switched to the use of standardized tests as a requirement for high school graduation in many states (Assessing Student Performance, 2000; Louis, Febey \& Schroeder, 2005). Unfortunately, instead of raising the bar for public education and encouraging high standards and excellence, these standardized exams resulted in more low income, minority students, and students with disabilities dropping out of school as a result of being unable to pass the tests (Amrein \& Berliner, 2002; Louis, Febey \& Schroeder, 2005; Voke, 2002).

\section{Minority Students and High-Stakes Testing}

Research shows mixed results regarding the effects of high-stakes testing for minority students. Cultural beliefs in many schools have long held negative attitudes concerning the academic abilities of Hispanic students (Olivos \& Quintana de Valladolid, 2005). McNeil (2002) labeled high-stakes testing as "the new discrimination for minority students," while Hargreaves and Fink (2006) stated that "standardization has become the 
enemy of diversity." In many schools, common curricula and learning standards as a result of high-stakes testing have institutionalized inequitable systems of academic tracking and uneven student achievement, with minority students being disproportionately represented in lower academic tracks (Oakes, Hunter Quartz, Ryan, \& Lipton, 2002).

Research by Amrein and Berliner (2002) found that high-stakes testing tends to be found in states with high percentages of African-American and Hispanic students. Skrla and Scheurich (2001) studied four school districts in Texas and noted that under the pressure of high-stakes testing associated with that state's accountability program, the test scores of minority students were raised. Skrla and Scheurich found evidence that the presence of high-stakes components forced the schools to change their thinking of how to educate minority students. They concluded that many districts were ignoring the poor academic achievement of minority students and children from low-income families as before the accountability system, many leaders did not have factual data on the extent of school failure in their districts (Skrla \& Scheurich, 2001).

Haney (2000) identified grade retention, testing exclusion for special education students, as well as English-proficiency exemptions as possible reasons for apparent increases in test scores in the state of Texas. Haney found that retention rates in ninth grade had increased substantially since the late 1980 s, with fewer than $50 \%$ of African American and Hispanic ninth graders progressing to high school graduation. He argued that part of the increase in pass rates of the state high-stakes test was attributable to the increase in the rates at which low-achieving students, minority and students in special 
education, were missing from the testing pool and hence the school accountability ratings.

After examining schools in Texas, Deere and Strayer (2001), found that schools were more likely to classify minority students as exempt if doing so would reduce the number of minority students tested to a low enough level that the schools' minority test scores would not be reported, thereby not negatively affecting the school's overall performance. Conversely, Carnoy and Loeb (2002) examined student gains on the NAEP mathematics test in all 50 states from 1996-2000 using a criterion-referenced measure of gain, specifically the change in the percentage of students meeting a desired achievement level, as the outcome variable. They found that students in states with stronger highstakes testing accountability systems made significantly higher gains on the eighth-grade national mathematics and that these gains were greater for minority students, thus narrowing the achievement gap.

Hanushek and Raymond (2003) reported positive achievement effects in their analysis of aggregate state-level NAEP mathematics data. They examined the relationship between state-level accountability policies and achievement for students at grades 4 and 8 and found that accountability policies appeared to increase state achievement gains. However, they also found that accountability policies did not close the gap in student learning, but actually increased it. This was determined by comparing pre- and post-data. In their study, African American and Hispanic students showed lower learning gains on each test when compared to their White counterparts.

Lee and Wong (2004) found no evidence that accountability policies resulted in test score gains or changes in the achievement gap, positive or negative. In a similar 
study, Nichols, Glass, and Berliner (2006) used regression analysis models and found that high-stakes testing and accountability policy effects were limited to fourth grade math. When the data were disaggregated by race/ethnicity, the findings indicated a higher performance gain for African American students than any other racial/ethnic subgroup. However, the researchers expressed a concern about the validity of these academic gains as a result of the exclusion of students, specifically SWD, at a higher rate during post testing.

High-stakes testing and accountability policies are stimulated by the 2002 passing of the No Child Left Behind Act. The theory behind accountability and testing is that schools and students who are held accountable to the measures of standard testing will increase educational output. However, the effects of high-stakes testing are mixed especially in respect to lessening the achievement gap with minority students. Some studies such as Skrla and Scheurich (2001) and Hanushek and Raymond (2003) suggest that students and schools make achievement gains in the presence of high-stakes testing. Skrla and Scheurich further emphasized that as a result of a change in thinking of how to educate minority students, this particular subgroup made achievements. Other research (Haney, 2000; Deere and Strayer, 2001; and Lee \& Wong, 2004) found no improvement or even negative consequences including the adjustment of the testing pool through student exclusions and placements within special education.

\section{Students with Disabilities and High Stakes Testing}

Historically, schools were not required to test SWD utilizing standardized tests; or if they did test them, the scores were not reported (Amrein \& Berliner, 2002; 2003; Carnoy \& Loeb, 2003; Glass \& Berliner, 2006). Losen (2002) and McLaughlin, Embler, 
Hernandez and Caron (2005) found that there was a significant increase in the referral rates of poorly performing students to special education prior to 1997 when the Amendments of the Individuals with Disabilities Act (IDEA) required that test scores of SWD must be included in the calculations of school district assessments. Similarly, Deere and Strayer (2001) and Helig and Darling-Hammond (2008) found that when Texas started counting the scores of SWD who did take the high-stakes test toward the schools' accountability ratings, the percentage of SWD who were classified as exempt from the test went up and a State-Developed Alternate Assessment for students with disabilities was created.

Figlio and Getzler (2002) and Jacob (2002) found similar results in their respective studies in Florida and Chicago. It was reported that special education enrollment went up after the introduction of high-stakes testing and students in tested grades were more likely than students in untested grades to be placed in special education. Also, students who scored lower on assessments were more likely to be placed in special education at a faster rate.

In another study, Sharpe and Hawes (2003) compared 180 students from two school districts (one that used high-stakes assessment and another that did not), in order to examine the extent to which students with disabilities are included in large-scale assessments. They found that there was no significance difference in students' academic progress as measured by grades between the two districts.

In 2005, Havner found that in Mobile County, Alabama, 27 out of the 33 schools that failed to make AYP would have otherwise passed had they not been forced to include test scores from special education students. In 2007, after a literature review on 
high-stakes testing in light of NCLB, Katsiyannis, Zhang, Ryan and Jones (2007)

concluded that high stakes testing increased: (a) participation of SWD in formal state assessments, (b) levels of performance by special education students in high-stakes testing, and (c) participation of special educators in training on standards and assessments. Negative consequences in high-stakes testing, per Katsiyannis et. al. include: (a) the challenge of SWD to achieve proficient levels as per their grade level, (b) SWD who fail make schools look less effective, and (c) students are stressed by taking tests and not accessing or reaching state standards.

Meeting the challenge of educating increasing numbers of special education students in our nation's schools is not simple. Test score results indicate that many students in special education continue to achieve well below their non-disabled peers in most subject areas and at virtually all grade levels. Given the potential negative consequences these assessments have for all stakeholders (i.e. students and schools), participation of SWD in high-stakes testing has been controversial with literature indicating an increase in student referral to special education (Losen, 2002; McLaughlin, Embler, Hernandez \& Caron, 2005; Deere \& Strayer, 2001; Helig \& Darling-Hammond, 2008; Figlio \& Getzler, 2002; and Jacob, 2002).

\section{Summary}

As the trend continues to educate a greater number of SWD in inclusive classroom settings, educators and researchers must continue to examine and seek to understand how the inclusion of disabled students in the general education classroom impacts academic achievement as measured by high-stakes, standardized tests, as testing has become the accountability measurement of most states. Additionally, emphasis must 
be made on students of different racial/ethnic backgrounds as they tend to have different levels of achievement and aspirations, reflecting both SES and cultural factors (Yair, 2000).

Current literature (Huber, Rosenfeld, \& Fiorello, 2001; Rea, McLaughlin, \& Thomas, 2002) reflects clear advantages of inclusion, such as exposing students with disabilities to the curriculum on grade-level, while exposing non-disabled students to a diverse population of peers. However, literature (Erickson, 2000; Haseldon, 2004) also makes clear the disadvantages of inclusion, as students with disabilities are exposed to a curriculum they may not master or may not clearly comprehend. The limited research has not specifically addressed the effectiveness of inclusion as an efficient and effective means of educating students with disabilities (Weiss, 2004). The academic successes and failures of students not only affect the individual students, but their performance on highstakes tests also affects their respective schools in terms of immediate and long-term consequences.

Research shows that student engagement is positively related to achievement and that disengagement leads to poor academic outcomes in a variety of subjects (Marks, 2000; Voelkl, 1997). Several studies have suggested that different ethnic groups may vary in their levels of sensitivity to instructional features or classroom conditions such as classroom procedures and discourse prompted by teachers (Uekawa et al., 2007; Yair, 2007), , thus their engagement and ultimately their performance on assessments.

The use of high-stakes testing and accountability policies are expanding as a means of improving academic outcomes for all students. High stakes testing has added increased expectations and accountability for all students and school districts. However, 
research shows mixed results regarding how high-stakes testing have affected outcomes for SWD and minority students.

No existing studies investigating ethnicity, English language learner status, or socioeconomic status of students- with or without disabilities- in co-taught classes, could be found by this researcher. Moreover, this researcher found no existing studies examining the differential achievement outcome of co-taught and non-co-taught classrooms, using the current standardized assessment in Florida, the Florida Comprehensive Achievement Test (FCAT).

For the purposes of this study, an analysis concerning the impact that the inclusion of Hispanic SWD in the general education classroom has on the academic achievement of the non-disabled student as well as the SWD in comparison to SWD within a resource setting were explored. Additionally, student behaviors related to academic achievement and the degree to which they occur in both settings among student subgroups were explored. 


\section{CHAPTER III}

\section{METHODS}

This chapter reviews the problem and purpose of this study as well as research questions and hypotheses. The methodology used to investigate each research question is explained. The population, method of data collection, and instrumentation are identified.

The purpose of this study was to examine classroom placement (inclusive versus non-inclusive) relative to the academic performance of Hispanic students with disabilities and their non-disabled peers in secondary reading and math classrooms. The study compared performance levels of four middle school student subgroups (students with disabilities in inclusive settings, students without disabilities in inclusive settings, students with disabilities in resource settings, and students without disabilities in general settings) each in their respective placements for two consecutive years, exploring existing practices within authentic settings as well as behaviors related to academic success exhibited by students within various educational placements. The following research questions were formulated to potentially achieve this purpose:

1. Does placement (inclusive versus non-inclusive classrooms) affect achievement change for urban low socio-economic Hispanic middle school students with and without specific learning disabilities in reading and math?

2. What interactive behaviors related to academic achievement are observable between student and teacher(s) within different educational placements for urban low-socio-economic Hispanic middle school students with and without specific learning disabilities? 


\section{Setting}

The settings for this study are two urban middle school located within MiamiDade County, Florida. Miami-Dade County houses the fourth largest school district and the second largest minority student population in the nation. The 2007 U.S. Census shows that $62 \%$ of Miami-Dade County residents are Hispanic, $19.8 \%$ African-American, and $17.9 \%$ White of Non-Hispanic origin. Some $30 \%$ of Miami-Dade County youth live in poverty, making Miami the poorest large city in the United States. Almost $60 \%$ of Miami-Dade County students are eligible for free or reduced-price lunches, with $70 \%$ of the African American students and $61 \%$ of the Hispanic students qualifying for the federal program (Miami-Dade County Public Schools [M-DCPS] Demographics Report, 2008b).

The first school, identified in this study as Middle School One, is located within a community where families represent $77 \%$ of the population, giving this particular area a higher than average concentration of non-single residences. As per the U.S. Census data (2008), $84 \%$ of the community population is Hispanic. Middle School One was built in 1954 and currently provides schooling for grades 6, 7, and 8. Since the year 1996, an average of 1,200 students per year have been enrolled in the school. The student body's racial/ethnic composition for the 2008-2009 school year was 94\% Hispanic, 5\% White, and $1 \%$ African-American. The school is a Title I school with $76 \%$ of the students, 852 students, qualifying for the free and reduced lunch program (M-DCPS, 2008a). 
Table 1

Middle School One Student Demographics

\begin{tabular}{cccccccccc}
\hline Grade & \multicolumn{1}{c}{ Caucasian } & \multicolumn{3}{c}{ African Am. } & \multicolumn{2}{c}{ Hispanic } & \multicolumn{2}{c}{ Asian/Indian } & Total \\
& Number & $\%$ & Number & $\%$ & Number & $\%$ & Number & $\%$ & Number \\
\hline 6 & 25 & 6 & 1 & 0 & 386 & 93 & 2 & 0 & 414 \\
7 & 18 & 5 & 2 & 1 & 360 & 94 & 1 & 0 & 381 \\
8 & 17 & 4 & 0 & 0 & 393 & 95 & 0 & 0 & 413 \\
Total & 60 & 5 & 3 & 1 & 1139 & 94 & 6 & 0 & 1208
\end{tabular}

Middle School One's Hispanic student population includes 13\% current enrollment in

Limited English Proficiency classes with 247 students, approximately 20\%, identified as

being born in another country other than the United States. Table 2 delineates the Special

Education Program and enrollment for Middle School One.

Table 2

Student and Exceptional Program Information

\begin{tabular}{lccc}
\multicolumn{1}{c}{ Program } & Students with & Students Enrolled in & \% School \\
& Exceptionality & Class Course & Population \\
\hline Educable Mentally Handicapped & 2 & 2 & 0.1 \\
Physically Impaired & 5 & 0 & 0.0 \\
Speech Impaired & 5 & 5 & 0.4 \\
Language Impaired & 2 & 2 & 0.0 \\
Emotionally Handicapped & 2 & 0 & 0.0 \\
Specific Learning Disabled & 151 & 59 & 3.9 \\
Gifted & 108 & 103 & 8.9 \\
Total & 255 & 176 & 13.3 \\
\hline $\begin{array}{l}\text { Note. The number enrolled in class course refers to the number of students with exceptionalities } \\
\text { participating in the state mandated curriculum regardless of educational setting. }\end{array}$
\end{tabular}


The second school, identified in this study as Middle School Two, is located within a community where families represent $68 \%$ of the population. Thus, the commonality with Middle School One, of being an area where there is a higher than average concentration of non-single residences exists. As per the U.S. Census data (2008), $85 \%$ of the community population is Hispanic. Middle School Two was opened in 1989 and currently provides schooling for grades 6, 7, and 8. An average of 1,100 students per year have been enrolled in the school since 2000. The student body's racial/ethnic composition for the 2008-2009 school year is 94\% Hispanic, 2\% White, and $3 \%$ African-American, see Table 3 . The school is a Title I school with $78 \%$ of the students qualifying for the free and reduced lunch program (M-DCPS, 2008a).

Table 3

Middle School Two Student Demographics

\begin{tabular}{cccccccccc}
\hline Grade & \multicolumn{3}{c}{ Caucasian } & \multicolumn{3}{c}{ African Am. } & \multicolumn{2}{c}{ Hispanic } & \multicolumn{2}{c}{ Asian/Indian } & Total \\
\hline & Number & $\%$ & Number & $\%$ & Number & $\%$ & Number & $\%$ & Number \\
\hline 6 & 9 & 3 & 10 & 3 & 302 & 93 & 5 & 2 & 412 \\
7 & 6 & 2 & 8 & 3 & 275 & 94 & 3 & 1 & 292 \\
8 & 7 & 2 & 8 & 2 & 308 & 95 & 5 & 2 & 403 \\
Total & 22 & 2 & 26 & 3 & 885 & 94 & 13 & 1 & 1107 \\
\hline
\end{tabular}

Middle School Two's Hispanic student population includes 15\% current enrollment in Limited English Proficiency classes with 208 students, approximately 22\%, identified as being born in another country other than the United States. Table 4 delineates the Special Education Program and enrollment for Middle School Two. 
Table 4

Student and Exceptional Program Information

\begin{tabular}{lccc}
\hline \multicolumn{1}{c}{ Program } & Students with & Students Enrolled in & \% School \\
& Exceptionality & Class Course & Population \\
\hline Educable Mentally Handicapped & 2 & 2 & 0.2 \\
Physically Impaired & 16 & 9 & 1.0 \\
Speech Impaired & 1 & 12 & 0.1 \\
Emotionally Handicapped & 14 & 55 & 1.3 \\
Specific Learning Disabled & 72 & 0 & 0.0 \\
Visually Impaired & 1 & 8 & 0.8 \\
Profoundly Mentally Handicapped & 9 & 79 & 8.4 \\
Gifted & 79 & 166 & 17.5 \\
Total & 194 & & \\
\hline
\end{tabular}

Note. The number enrolled in class course refers to the number of students with exceptionalities participating in the state mandated curriculum regardless of educational setting.

Florida schools are assigned a grade based upon student achievement data from the FCAT. School grades communicate school performance relative to state standards and are calculated based on annual learning gains of each student toward achievement of Sunshine State Standards, the progress of the lowest quartile of students, and the meeting of proficiency standards. Middle School One and Middle School Two have each been recognized as grade "A" schools (Florida Department of Education, 2009), yet both schools are classified as Schools in Need of Improvement (SINI) as SWD and ESOL students have not made AYP on the FCAT. 
Each of the classes utilized for this study was characterized as either general education, inclusive, or resource room. The co-taught inclusion classes within both settings contain approximately 32 students with one-third of the students identified as having a disability. General education classes typically had 25 students. Conversely, classes deemed as resource were those taught by a special education teacher that occurred in settings other than a general education classroom with approximately 18 students per classroom.

\section{Research Design}

In order to investigate the research questions for the present study, a combination of statistical and case study methods using a mixed method study design was employed (Newman \& Benz, 1998). The present study utilized data from the quantitative strand, the first strand, to guide the qualitative strand, the second strand (Tashakkori \& Newman, in press). Statistical investigations of the relations between placement, grade level, and mean change in FCAT test scores in reading and mathematics from the 2008-2009 to 2009-2010 administration were conducted.

The participants in this study consisted of 80 seventh and eighth grade students per school for a total of 160 students. Within each school, the population studied consisted of 20 students without disabilities who were enrolled in general education reading and math classes; 20 students without disabilities who were enrolled in co-taught inclusion reading and math classes; 20 SWD who were enrolled in co-taught inclusion reading and math classes; and 20 SWD who were enrolled in reading and math resource classes. The use of quantitative measures through data analysis of mean learning change from the 2008-2009 FCAT administration to the 2009-2010 FCAT administration in the 
areas of reading and mathematics guided the researcher in answering Research Question 1. The data also assisted in the selection of the 16 participants who were used for the descriptive qualitative measures through structured classroom observations focusing on student-teacher interactive behaviors that were used to address Research Question 2. In Strand I, two (reading and math), Three-Way Mixed Analysis of Variance (ANOVAs) were used. The factors are placement (inclusion or non-inclusive), grade level (seventh or eighth grade), and SLD (yes or no). The dependent variable for the study was the FCAT mean learning change in reading and math respectively. The ANOVAs compared the amount of between group variance on the students' mean change scores on the 2008-2009 FCAT administration from the 2009-2010 FCAT administration in the areas of reading and mathematics for each group of students (SWD or students without disabilities), for each grade, and by grade level interactions. It was treated as a continuous variable with a potential range of 0 to 1500 . (While steps to control for variables among the settings have been taken, exploratory data analysis based on the study were amended accordingly.)

In Strand II, case study methods was used to interpret student interactions with teachers within a real-life context (Yin, 2003). The case study methods identified factors that may have contributed to improved student achievement within the real-life context of a selected middle school and school district. In addition, the case study methods allowed the researcher to present rich descriptions of the setting and the students' interactions (Bogdan \& Biklen, 2007), specifically from classroom observations, that led to more indepth information about specific student-teacher interactive behaviors that occurred in each placement. This information may explain differences in learning gains for students 
with and without disabilities. Case study research may provide explanations or patterns for the studied phenomenon (Gall, Gall, \& Borg, 2003) through detailed explanations. In this study, the researcher selected case study methods to study the phenomenon within its natural setting and to gain insights and detailed descriptions to identify emerging themes. The observation protocol that was used to conduct the observations was derived from Yin (1994) and Creswell (2003). Yin (1994) suggests the researcher possess or acquire the ability to interpret responses. The researcher has had 15 years of experience in the field of special and inclusive education. Creswell (2003) recommends a specific application of procedures be followed. For this strand of the research, the following procedures were used: organizing and preparing of field notes; reflecting of the general sense of the findings; coding; rendering of the information and emerging themes; representing of the findings of the analysis through a narrative to convey the findings of the analysis; and interpreting the findings of the literature in comparison to the findings of the study. Observations focused on student-teacher interactions including teacher-initiated and student-initiated behaviors.

Specific characteristics of engagement by the student were observed, including body language, level of focus on the learning activity, level of verbal participation through the sharing of opinions, and the level of completion and/or engagement in a task. The researcher had no control over the student-teacher interactions, which is a characteristic of case studies. 


\section{Strand I}

\section{Participants}

The population of interest for Strand I was Hispanic students attending Middle School One and Middle School Two. This population of urban schools was selected because research in inclusion has frequently been aimed at suburban rather than urban school populations. Investigations, especially at the middle school grade levels, are also limited. On average, study participants were 14 years old and in seventh or eighth grade. All of the students were Hispanic and of low socio-economic status as evidenced by free and/or reduced lunch status.

The four subgroups analyzed had equal group sizes. There was a sample of 160 students so that there were equal number of students in each subgroup, for homogeneity of variance: 10 each of students with disabilities in a resource setting, students with disabilities in a co-taught inclusive setting, non-disabled students in a co-taught inclusive setting, and non-disabled students in general education setting per grade level (i.e. seventh and eighth grade), per school (i.e. Middle School One, Middle School Two), all of whom had been enrolled within their assigned educational setting since the beginning of the 2008-2009 school year without a change in services.

SWD who participated in the study were identified as having a specific learning disability through the referral and assessment procedures as outlined by the federal and state regulations. Research on outcomes associated with the inclusion of students with different types of disabilities has suggested that those with behavioral, social, and emotional difficulties may have more difficulties within an inclusion program than other groups of students with disabilities due to the nature of their disabilities (Dyson, Farrell, 
Polat, Hutchenson, \& Gallanaugh, 2004). Therefore, for the purposes of this study, students identified as having solely a specific learning disability were included and referred to as students with disabilities.

\section{Criteria for Sample Selection}

The first step in data collection involved identifying seventh and eighth grade inclusive reading and math classrooms, seventh and eighth grade resource math and reading classes, and seventh and eighth grade general education reading and math classes within the two middle schools. Students who did not attend the same educational setting for two consecutive years were excluded from the study as were students who did not participate in the state assessment for the 2008-2009 and 2009-2010 year. Additionally, students not proficient with English as denoted by an English for Speakers of Other Languages (ESOL) Level of 4 or below were excluded from the selected student participation to minimize variability as a result of language difficulties. Emphasis was placed on ethnicity (Hispanic origin), English proficiency status for students exited from the ESOL program, number of absences within the school year, and disciplinary actions taken.

\section{Data Collection}

The County maintains data sets of learning changes of all schools within its district by school year, as well as student scores. This source of data was selected due to its availability and relevance to the study. Assessments used for this evaluation were administered by the school district between 2008 and 2009. Class placement, specifically resource room, inclusive placement, or general education setting, are the independent 
variables and performance changes on the reading and math FCAT as per differences in individual students' developmental scale score, the dependent measure.

\section{Measures and Variables}

FCAT scores. The FCAT is part of Florida's overall plan to increase student achievement by implementing higher standards. The FCAT is used to assess the levels of students; knowledge and skill in reading and mathematics at grades 3-10. Each item on the FCAT for each subject and grade is designed to measure a specific skill. Tables 5 and 6 present the content categories for the FCAT Reading and Mathematics tests for grades 7 and 8.

Table 5

FCAT Reading

$\begin{array}{lllll}\text { Grade } & \text { Specific Skill } & \text { Item } & \text { Item } & \text { Item }\end{array}$

7-8 Words and Phrases in Main Idea, Plot, Comparisons Reference and

Context and Purpose and Research

Cause/Effect

Table 6

FCAT Mathematics

\begin{tabular}{|c|c|c|c|c|c|}
\hline Grade & Specific Skill & Item & Item & Item & Item \\
\hline \multirow[t]{3}{*}{$7-8$} & Number Sense, & Measurement & Geometry & Algebraic & Data \\
\hline & Concepts, and & & and Spatial & Thinking & Analysis and \\
\hline & Operations & & Sense & & Probability \\
\hline
\end{tabular}


Table 7 displays the number of minutes allowed for test takers without accommodations. IEPs may reflect additional time for SLD on FCAT.

Table 7

Duration of FCAT by Grade Level

\begin{tabular}{ccc}
\hline Grade & Reading & Mathematics \\
\hline 7 & 120 minutes & 120 minutes \\
8 & 160 minutes & 160 minutes \\
\hline
\end{tabular}

Scores on the FCAT are reported in terms of scaled scores (range 100-500) and achievement levels. Students can score between 1 (lowest achievement score) and 5 (highest achievement score; Florida Department of Education [FDOE], 2001, 2004). However, the cutoff scores for each level vary according to grade and the mean and standard deviation of scores varies with each administration (FDOE, 2002, 2006). Because it is difficult to determine student growth year-to-year using standard or scale scores, developmental scores are also provided. This is a value-added assessment system added in 2002 to the FCAT score reporting procedures. Developmental scores range from 0 to 3000 , allowing the tracking of an individual student's achievement progress and growth over time (FDOE, 2004). As student achievement improves (as measured by FCAT scores), the developmental scores rise. If a student regresses from one year to the next, the developmental score decreases. Developmental scale scores are available only for FCAT reading and mathematics and cannot be determined for FCAT science and writing because students are not tested in these subjects at each grade level. For the 
purposes of this study, the change in developmental scale scores were used to measure the mean learning change of the 2008 and 2009 administration of the FCAT.

\section{Procedures}

The statistical procedures utilized in this study are descriptive and inferential statistics. Descriptive statistics were used to summarize and organize the data (Gall et al., 1996). Descriptive statistics are concerned primarily with reporting the condition of existing phenomena and are used to reduce and organize student data. Quantitative data were analyzed using Statistical Package for Social Studies, Version 16 (SPSS). For the interpretation of the data, descriptive and inferential data analysis was used.

Consent to access student performance data were obtained through M-DCPS district via proper procedures. Permission from the district and participating schools was secured to use routinely generated demographic reports for information concerning the variables of course codes, race/ethnicity, gender, and SES. A database containing information about students was created using SPSS and included the following information: gender, grade level, ethnicity, disability category, excused absences, unexcused absences, outdoor suspensions, program placement, reading developmental scale score for the 2008-2009 year, reading developmental scale score for the 2009-2010 year, math developmental scale score for the 2008-2009 year, and math developmental scale score for the 2009-2010 year. Students were identified based on the sample criteria. Confidentiality was maintained by replacing student name and identification number with a sequential number based on the number of students in the study (i.e., 1, 2, 3...). All data input was reviewed for entry errors and completeness. 
The data obtained from the school district (grade level, gender, disability, socioeconomic level, language proficiency) were imported, re-coded, and analyzed using SPSS software. Excel was used to construct and analyze contingency tables. The data were analyzed for relationships between educational class setting and achievement in student performance levels.

The study consisted of a total of 160 student subjects, 80 students from each of the school sites. Students were assigned to groups based upon their educational placement and status (i.e., students with disabilities, students without disabilities). Groups consisted of: (a) 10 students with disabilities in an inclusion setting, (b) 10 students without disabilities in an inclusion setting, (c) 10 students with disabilities in a resource setting, and (d) 10 students without a disability in a general education setting for each school site per grade level (seventh and eighth grades) totaling 80 students per site and a combined 160 student participants.

In order to provide a uniform, formal procedure in order to establish whether the mean difference in this study was significantly greater than can be explained by sampling error, f-tests using the independent measures design for between subjects was used (Gravetter \& Wallnau, 2005). Descriptive statistics are the most appropriate for comparing the outcomes for all groups. The f-tests were used to determine the statistical difference of the mean reading scores and the mean mathematics scores on the FCAT concerning student achievement in reading and mathematics for the treatment group and the comparison group. An alpha level of .05 was used on all tests.

Two, Three-Way Mixed Analysis of Variance (ANOVAs) were used to analyze the data analyses. The factors were: placement (inclusion or non-inclusive), grade level 
(seventh and eighth grade), and SLD (yes or no). The dependent variable for the study was the FCAT mean learning change in reading and math respectively. The ANOVA compared the amount of between group variance on the students' mean change scores on the 2008-2009 FCAT administration from the 2009-2010 FCAT administration in the areas of reading and mathematics for each group of students (SWD or students without

disabilities), for each grade, and by grade level interactions. It was treated as a continuous variable with a potential range of 0 to 1500 . (While steps to control for variables among the settings were taken, exploratory data analysis based on the study was amended accordingly.)

ANOVA is a general technique that can be used to test the hypothesis that the means between two or more groups are equal, under the assumption that the sampled populations are normally distributed, independent, variances of the groups must be equal, and groups must have the same sample size. Two, Three-Way Mixed ANOVAs were used to determine if significant difference existed among the independent variables, such as gender and grade level of the different subgroups within the study. Post-hoc analyses of the impact of demographic information were completed. Multiple displays such as charts and tables were used to present findings in Chapter 4.

\section{Data Analysis}

The following calculations examined the research questions of this study:

1. f-test analyses were conducted on student demographic data of the groups in terms of their disability/non-disability status and grade level.

2. The mean achievement change score for Hispanic middle school students with and without specific learning disabilities in specific educational program 
placements (inclusive versus non-inclusive classrooms) in reading and math were analyzed using two, Three-Way Mixed ANOVAs.

All 160 students took the 2008-2009 FCAT and the 2009-2010 FCAT. Thus, the scores were normally distributed. The dependent variable was the mean learning change on the developmental scores of the 2009 FCAT and the 2010 FCAT. Mean scores for the initial and post-test were analyzed using F-tests. Tables 8 and 9 show the factor design. Table 8

Factor Design for Math

\begin{tabular}{llccc}
\hline & Subgroup & Grade & \multicolumn{2}{c}{ Setting } \\
\hline SWD & Student Without & $7-8$ & Inclusion Class & Non-inclusion \\
& Disability & & & Class
\end{tabular}

Note. There are 3 parameters, setting, grade, and FCAT subject, defining 4 groups of replicate samples with common parameter values (inclusion versus resource class, reading or math).

Table 9

Factor Design for Students without Disabilities

\begin{tabular}{llccc}
\hline & Subgroup & Grade & \multicolumn{2}{c}{ Setting } \\
\hline SWD & Students Without & $7-8$ & Inclusion Class & Non-inclusion \\
& Disabilities & & & Class
\end{tabular}

Note. There are 3 parameters, grade, setting and FCAT subject, defining 4 groups of replicate samples with common parameter values (inclusion versus general education class, reading or math).

\section{Strand II}

\section{Setting}

This strand of the study utilized purposeful sampling by gathering in-depth data from a small number of information-rich cases. While purposeful sampling may pose 
some limitations because the information attained was from a specific site, this approach provided opportunities to gain in-depth insights regarding student engagement within varying educational settings (Patton, 2000). This study purposefully sought a school located in an urban setting with Hispanic students of low socio-economic status as indicated by $70 \%$ or more of the student population receiving free and reduced lunch. Additionally, the setting for this study was selected based on permission of site administration. Middle School One, a middle school in the Miami, Florida, metropolitan area, from Strand I, met these criteria and thus was the setting for this strand of the study.

\section{Participants}

The population of interest for this strand of the study was Hispanic students attending Middle School One. On average, study participants were 14 years old and in eighth grade in the 2009-2010 school year and would have been seventh graders in Middle School One in the 2008-2009 school year.

Two students representing the highest and lowest change in developmental scores on the FCAT 2008 and 2009 administration for each subject (reading and math) from each subgroup (student with a disability in a resource setting, student with a disability within an inclusion setting, non-disabled student within an inclusion setting, and nondisabled student within a general education setting) totaling 16 students, receiving educational services for both reading and math within the same setting for two consecutive years within the same middle school participated in the research. Table 10 shows student participant status and settings. 
Table 10

Student Participant Status and Setting

\begin{tabular}{|c|c|c|}
\hline \multirow[t]{2}{*}{ Status } & \multicolumn{2}{|r|}{ Setting } \\
\hline & Inclusion Class & $\begin{array}{l}\text { Unique Class (Resource Class } \\
\text { or General Education Class) }\end{array}$ \\
\hline Student with Disability & High Scoring in Reading & \\
\hline Student with Disability & Low Scoring in Reading & \\
\hline Student with Disability & & High Scoring in Reading \\
\hline Student with Disability & & Low Scoring in Reading \\
\hline Student with Disability & High Scoring in Math & \\
\hline Student with Disability & Low Scoring in Math & \\
\hline Student with Disability & & High Scoring in Math \\
\hline Student with Disability & & Low Scoring in Math \\
\hline Student without Disability & High Scoring in Reading & \\
\hline Student without Disability & Low Scoring in Reading & \\
\hline Student without Disability & & High Scoring in Reading \\
\hline Student without Disability & & Low Scoring in Reading \\
\hline Student without Disability & High Scoring in Math & \\
\hline Student without Disability & Low Scoring in Math & \\
\hline Student without Disability & & High Scoring in Math \\
\hline Student without Disability & & Low Scoring in Math \\
\hline
\end{tabular}


Students with SLD who participated in the study were identified as having a disability through the referral and assessment procedures as outlined by the federal and state regulations. Research on outcomes associated with the inclusion of students with different types of disabilities has suggested that those with behavioral, social and emotional difficulties may have more negative effects within an inclusion program than other groups of students with disabilities (Dyson, Farrell, Polat, Hutchenson, \& Gallanaugh, 2004). Therefore, for the purposes of this study, students identified as having solely SLD were included in the disability subgroup.

Four teachers, two general education teachers certified in and teaching reading and math respectively for seventh and eighth grade students within a co-taught inclusion class and a general education setting and two special education teachers co-teaching in a seventh and eighth grade reading or math class who additionally teach students with disabilities reading or math in a resource room setting, participated in this study. These four teachers were selected as a result of their teaching assignments (i.e., the general education reading teacher teaches within the inclusion setting and the general education setting; the special education teacher who co-teaches reading within the inclusion setting also teaches reading within the resource setting, etc.) and certifications to eliminate variability among teachers. Both general education teachers were certified in the content area (i.e. reading or math) assigned to them by the school. The special education teachers were either certified in the content area (i.e. reading, math, or middle school integrated certified) or considered highly qualified within the content area assigned to them by the school as a result of years of teaching. Table 11 shows teacher participant status and setting. 
Table 11

Teacher Participant Status and Setting

\begin{tabular}{lcc}
\hline \multicolumn{1}{c}{ Participant } & \multicolumn{1}{c}{ Content Area \& Setting } & Years Teaching \\
& & Experience \\
\hline Mr. Sanchez & Reading, Inclusion, and General Education & 15 \\
Ms. Martinez & Reading, Inclusion, and Resource Room & 18 \\
Mr. Garcia & Math, Inclusion, and General Education & 13 \\
Ms. Rodriguez & Math, Inclusion, and Resource Room & 20 \\
\hline Note. Pseudonyms were used for confidentiality purposes. &
\end{tabular}

\section{Criteria for Sample Selection}

The first step in this process involved identifying Hispanic students from each of the subgroups: (1) eighth grade students with learning disabilities who had participated and continued to be enrolled within inclusive reading and math classrooms; (2) eighth grade students with learning disabilities who had participated in and continued to be enrolled in resource math and reading classes; (3) eighth grade non-disabled students who had participated and continued to be enrolled within inclusive reading and math classrooms; and (4) eighth grade general education students who had participated in and continued to be enrolled in general education reading and math classes for the past two consecutive school years within Middle School One. Emphasis was placed on ethnicity, language proficiency status with students exited from the ESOL program, number of absences within the school year, and disciplinary actions taken. From those identified students from each setting, the second step was to select the Hispanic student from each setting who scored the highest average on developmental scale score changes for the 
2009 FCAT and the other student who scored the lowest average on developmental scale score changes for the 2009 FCAT in reading and math respectively.

After identifying the students who were to participate within the study, corresponding teachers were then identified. The identification of teachers who met the criteria of teaching both an inclusion class and a unique setting class (i.e., resource room setting or a general education setting) reduced the number of possible participants significantly. Additionally, emphasis was placed on teachers having a minimum of 5 years of experience teaching their particular content area.

\section{Procedures}

An observational case study guided this strand of the study in order to attempt to describe the meaning of events and interactions (Bogdan \& Biklen, 2007) among 16 Hispanic students within their respective educational settings. It offers an in depth look at a phenomenon in real-life settings using rich descriptions (Gall, Gall, \& Borg, 2007). Classroom observations which took place for two 30-minute sessions for two students in a reading and math class respectively for each setting (resource classroom, inclusive classroom, and general education classroom) with emphasis on verbal and non-verbal cues of the selected student participants with the purpose of seeking information regarding observable interactive behaviors between student and teacher in each of the settings and its' impact on academic achievement.

The observational protocols used to conduct the observations were derived from Yin (1994) and Creswell (2003). Yin (1994) has suggested the researcher possess or acquire the ability to interpret responses. The researcher has had 15 years of experience in the field of special and inclusive education. Creswell (2003) has recommended a 
specific application of procedures be followed. For this strand of the research, the following procedures were used: the organization and preparation of field notes; a general sense of the findings through reflection, coding, detailed rendering of the information, and emerging themes; a representation through a narrative to convey the findings of the analysis; and an interpretation derived from comparisons of the findings to the literature. Observations focused on student-teacher(s) interactions with characteristics of engagement through positive body language exhibited by the student, consistent focus on the learning activity, verbal participation through the sharing of opinions, and student confidence to complete and/or engage in a task. The researcher had no control over the student-teacher(s) interactions, which is a characteristic of case studies. Had a pattern not been identified, as cited by Newman (1998), additional observations would have occurred.

Prior to conducting any observations, informed consent from the Institutional Review Board (IRB) in accordance to their guidelines was attained. After receiving approval from the district, the school-site administrator was contacted in order to encourage the participation and flexibility required from the school staff.

Regarding ethical matters, consent was obtained through M-DCPS via proper procedures and permission from Middle School One site administration obtained to perform classroom observations. Students were identified based on sample criteria utilizing the school's records. All 16 identified students, their parents, and pertinent classroom teachers were addressed individually and explained the rationale and purpose of the study prior to the observations. The home language of the students and parents were utilized to facilitate this process as the researcher is fluent in English and Spanish. 
The purpose of the study and the need for their participation were explained to the teachers and students within the school environment before administration. Parents/Guardians were contacted via telephone. A letter of consent was given to each family (see Appendix A). Permission forms included a pre-stamped envelope to facilitate return. Of the 16 students contacted for this study, 14 returned the consent form within 7 days. For students whose consent forms were not returned within seven days, a second consent form and phone call was made. The aforementioned consent forms were returned within three days. After parental consent was obtained, students were given an assent form asking them to participate. After answering questions relating to participation within the study, namely how participation within the study would not affect their grades, all students signed and returned the assent forms immediately.

It is imperative that confidentiality be protected at all times. As such, all participants and school remain confidential. Students and teachers were randomly assigned a pseudonym and this identifier was used for all data collected. Table 12 identifies pertinent student and teacher information. Participation in the research was optional. Participants had the option to choose not to participate at any time throughout the research, without any negative repercussions. However, no participants expressed a desire to terminate or halt participation. 
Table 12

Participant Characteristics

\begin{tabular}{|c|c|c|c|c|}
\hline Teacher & Students & Setting & Level & Characteristics \\
\hline \multirow{3}{*}{ Mr. Sanchez } & Jose & $\mathrm{R}, \mathrm{G}$ & High & GE, Male \\
\hline & Oscar & $\mathrm{R}, \mathrm{G}$ & Low & GE, Male \\
\hline & Isabella & $\mathrm{R}, \mathrm{I}$ & High & GE, Female \\
\hline \multirow{4}{*}{$\begin{array}{l}\text { Mr. Sanchez } \\
\text { and } \\
\text { Ms. Martinez }\end{array}$} & David & $\mathrm{R}, \mathrm{I}$ & Low & GE, Male \\
\hline & Johnny & $\mathrm{R}, \mathrm{I}$ & High & SWD, Male \\
\hline & Christopher & $\mathrm{R}, \mathrm{I}$ & Low & SWD, Male \\
\hline & Julio & $\mathrm{R}, \mathrm{RR}$ & High & SWD, Male \\
\hline \multirow[t]{2}{*}{ Ms. Martinez } & Mario & $\mathrm{R}, \mathrm{RR}$ & Low & SWD, Male \\
\hline & Jonathan & $\mathrm{M}, \mathrm{G}$ & High & GE, Male \\
\hline \multirow[t]{2}{*}{ Mr. Garcia } & Nancy & M, G & Low & GE, Female \\
\hline & Victor & M, I & High & GE, Male \\
\hline \multirow{4}{*}{$\begin{array}{c}\text { Mr. Garcia } \\
\text { and } \\
\text { Ms. Rodriguez }\end{array}$} & Roxanna & M, I & Low & GE, Female \\
\hline & Jorge & $\mathrm{M}, \mathrm{I}$ & High & SWD, Male \\
\hline & Claudia & $\mathrm{M}, \mathrm{I}$ & Low & SWD, Female \\
\hline & Melissa & M, RR & High & SWD, Female \\
\hline Ms. Rodriguez & Carlos & $\mathrm{M}, \mathrm{RR}$ & Low & SWD, Male \\
\hline
\end{tabular}

Key. $\mathrm{R}=$ Reading, $\mathrm{M}=$ Math, $\mathrm{I}=$ Inclusion Setting, $\mathrm{G}=$ General Education Setting, $\mathrm{R}$ =Resource Room Setting, GE $=$ General Education student, $\mathrm{SWD}=$ Student with Disability

Observations created an opportunity to witness student-teacher interactions in the various educational settings. All observations were conducted in the student's normal learning environment and lasted approximately 30 minutes per student. Field notes were 
used to document interactions between teachers and students and among students in a natural setting. The observation protocol of field notes came from models developed by Patton (2000) who recommends scripting versus a checklist to make certain the depth of each observed setting is captured. As such, open-ended observation logs were maintained to allow field notes to be scripted freely without the burden of specific coding during the observation. Notes from the log were transcribed within a 24-hour period after each observation to capture as much detailed information as possible. To increase reliability, member checking was utilized. Member checking is the sharing of final descriptions with the participants to see if the participants feel the descriptions are accurate (Creswell, 2003).

\section{Data Analysis}

Developing themes emerging from the field notes were coded. As per Fossey, McDermott, and Davidson (2002), the researcher's thoughts and reflections were employed in the process of coding to develop an understanding of the data. Following the coding, descriptions, and categorizing, findings were represented by way of a narrative. A narrative analyzing the phenomenon includes direct citations from participants and a comparison of results from the study and literature on the topic of student engagement (Cresswell, 2004). By linking the categories and concepts, theories were generated to answer the research questions (Merriam, 1998). Table 13 describes specific steps used throughout the data analysis process.

So that the interpretation was a valid and reliable account, each teacher(s) was asked to examine the analysis. This strategy served as a triangulation mechanism to corroborate findings (Newman, 1998). Additionally, another researcher trained in the 
process, who was not involved in the data analysis process, was asked to give an opinion on the accuracy of the match between themes and data.

Table 13

Detailed Process of Data Analysis for Strand II

\begin{tabular}{ll}
\hline \multicolumn{1}{c}{ Steps } & \multicolumn{1}{c}{ Description } \\
\hline Organize and Prepare & Sort and arrange the field notes \\
Representation & Narrative passage to convey the finding of the analysis \\
& Detailed discussion of themes \\
& Discussion with interconnecting themes \\
& Present a process model grounded in theory \\
& Lessons learned/ Personal interpretations \\
& Meaning derived from comparison of finding to literature
\end{tabular}

Source: Creswell (2003)

\section{Summary}

The general purpose of this study was to explore the academic achievement of SLD and non-disabled students educated in inclusive programs compared to SLD and non-disabled students not educated in inclusive settings. The intent of the study was also to gain information regarding what observable interactions between students and teacher are visible for academic achievement within the various settings for Hispanic students for SWD and non-disabled students.

This chapter highlighted the subjects, instrumentation, procedures and statistical treatment that were used in the research for this study. Quantitative analysis and program descriptions were presented within this study. The utilization of both types of analysis was intended to lend further validity to the findings of the study. Data for Strand I of the 
study were obtained from comparison of changes within developmental scale scores on the 2008-2009 and 2009-2010 FCAT for the four subgroups using f-tests and ANOVAs. A qualitative method of collecting and interpreting data was used to examine student behaviors related to academic achievement. Presentation of the findings and discussion are forthcoming in the next two chapters. 


\section{CHAPTER IV}

\section{RESULTS}

The number of racial/ethical minority students in public schools is growing, fueling the current accountability agenda concerning the impact of different educational settings on the academic achievement of minority students with and without disabilities. Consequently the purpose of this study was to examine classroom placement (inclusive versus non-inclusive) relative to the academic performance of Hispanic students with SLD and their non-disabled peers in secondary content area classrooms. Lagging pass rates that have traditionally characterized the achievement performance of this group of students has become synonymous with school failure according to NCLB mandates. NCLB requires the use of scientifically-based research to obtain valid insights about an educational practice or program and to determine the impact on intended outcomes (Mertens \& McLaughlin, 2004). The question about the relationship of inclusive practice in middle schools to achievement in reading and mathematics was examined in this study to provide valuable information for school leaders. The results of this study are presented with this in mind.

The results of this study sought to: (a) identify whether educational placement affects student performance and (b) investigate which observable student interaction with the teacher(s) within the classroom setting are related to academic achievement and present within various settings. In examining this issue, two research questions were posed:

1. Does placement (inclusive versus non-inclusive classrooms) affect achievement change for urban low socio-economic Hispanic middle school students with and without specific learning disabilities in reading and math? 
2. What interactive behaviors related to academic achievement are observable between student and teacher(s) within different educational placements for urban low-socio-economic Hispanic middle school students with and without specific learning disabilities?

The participants for both strands of the study consisted of a heterogeneous population of middle school Hispanic students with and without SLD of low socio-economic status as evidenced by free and/or reduced lunch status. On average, study participants were 14 years old and all were in seventh or eighth grade in co-taught inclusive classrooms, general education classrooms, or resource room classrooms, for math and reading.

\section{Strand I}

The achievement was determined for the four middle school student subgroups (students with disabilities in inclusive settings, students without disabilities in inclusive settings, students with disabilities in resource settings, and student without disabilities in general education settings) in two content areas: reading and math. The relationships were examined by engaging statistical controls for gender, English language learner status, and socio-economic status, while controlling for ethnicity. Student academic performance was determined according to the mean FCAT developmental scores for the 2008-2009 and 2009-2010 school years in reading and math. The f-test for two independent samples was used to determine the statistical difference of the mean reading and math scores on the FCAT for SWD and non-disabled peers. An alpha level of 0.05 was used on all tests. The Scheffe post-hoc analysis was applied with an alpha level 0.05 when significance in the ANOVA was found. 
Variables within the study. The mean learning change on the Developmental Scale Scores on the 2008 FCAT and the 2009 FCAT, grade level, and setting were addressed as quantitative variables for this study. The dependent variables used in this strand of the study were the FCAT reading and math developmental scale scores for the 2008-2009 and 2009-2010 school year. FCAT's purpose is to measure performance in the core areas of the state-mandated curriculum.

The sample utilized in this strand of the study was students assigned to groups based upon their educational placement and status (i.e., students with disabilities, students without disabilities). Educational placement and status were independent variables in this study. Groups consisted of (a) 10 students with SLD in an inclusion setting, (b) 10 students without disabilities in an inclusion setting, (c) 10 students with SLD in a resource setting, and (d) 10 students without a disability in a general education setting for each school site per grade level (seventh and eighth grades) totaling 80 students per site and a combined 160 student participants. Tables 14 and 15 provide a statistical description of the variables analyzed. Figures 1 and 2 depict the findings in terms of mean difference scores per grade level $\left(7^{\text {th }}\right.$ or $8^{\text {th }}$ grade), setting (inclusive or noninclusive) and disability (SWD or student without disability). The source for the analyzed variables was provided by the school district's database system. The grade of the student was a categorical independent variable analyzed in this study. Students were identified as either seventh or eighth graders based on their assigned grade level during the 2008-2009 school year. 
Table 14

Descriptive Statistics for Math Developmental Scores

\begin{tabular}{|c|c|c|c|c|c|}
\hline Inclusion & Grade & Disability & Mean & Std. Deviation & $\mathrm{N}$ \\
\hline \multirow[t]{9}{*}{ No } & Grade 7 & Non-Disabled & 143.85 & 204.064 & 20 \\
\hline & & SWD & -59.75 & 186.112 & 20 \\
\hline & & Total & 42.05 & 218.611 & 40 \\
\hline & Grade 8 & Non-Disabled & -10.65 & 134.520 & 20 \\
\hline & & SWD & 103.35 & 324.618 & 20 \\
\hline & & Total & 46.35 & 251.964 & 40 \\
\hline & Total & Non-Disabled & 66.60 & 187.680 & 40 \\
\hline & & SWD & 21.80 & 273.922 & 40 \\
\hline & & Total & 44.20 & 234.390 & 80 \\
\hline \multirow[t]{9}{*}{ Yes } & Grade 7 & Non-Disabled & 53.70 & 119.410 & 20 \\
\hline & & SWD & 70.30 & 193.980 & 20 \\
\hline & & Total & 62.00 & 159.214 & 40 \\
\hline & Grade 8 & Non-Disabled & 57.25 & 186.255 & 20 \\
\hline & & SWD & 122.65 & 285.963 & 20 \\
\hline & & Total & 89.95 & 240.492 & 40 \\
\hline & Total & Non-Disabled & 55.48 & 154.436 & 40 \\
\hline & & SWD & 96.48 & 242.638 & 40 \\
\hline & & Total & 75.98 & 203.135 & 80 \\
\hline \multirow[t]{9}{*}{ Total } & Grade 7 & Non-Disabled & 98.78 & 171.224 & 40 \\
\hline & & SWD & 5.27 & 198.855 & 40 \\
\hline & & Total & 52.03 & 190.284 & 80 \\
\hline & Grade 8 & Non-Disabled & 23.30 & 164.008 & 40 \\
\hline & & SWD & 113.00 & 302.112 & 40 \\
\hline & & Total & 68.15 & 245.712 & 80 \\
\hline & Total & Non-Disabled & 61.04 & 170.864 & 80 \\
\hline & & SWD & 59.14 & 259.841 & 80 \\
\hline & & Total & 60.09 & 219.210 & 160 \\
\hline
\end{tabular}


Figure 1

Mean Math Difference Developmental Scores

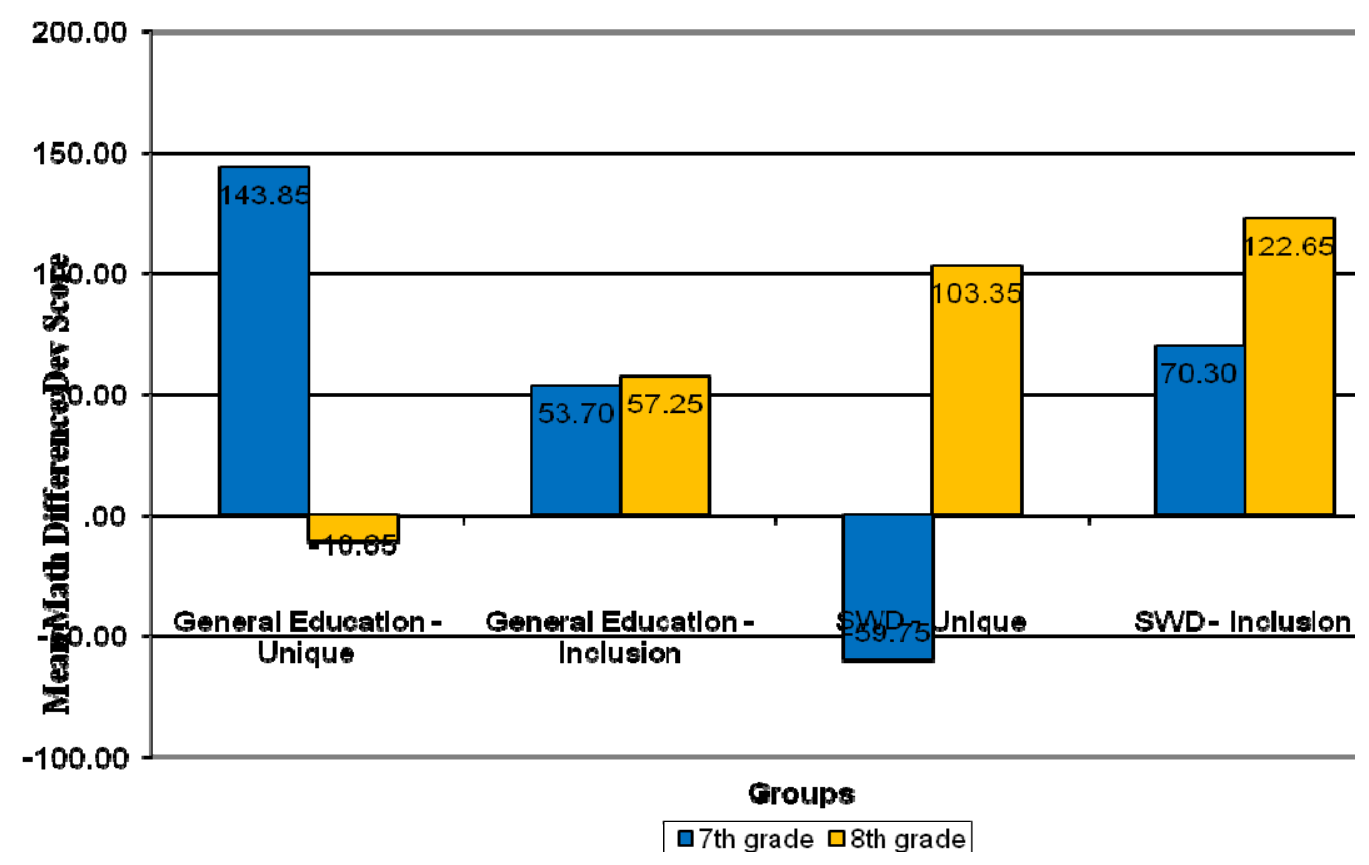

Figure 2

\section{Mean Reading Difference Developmental Scores}

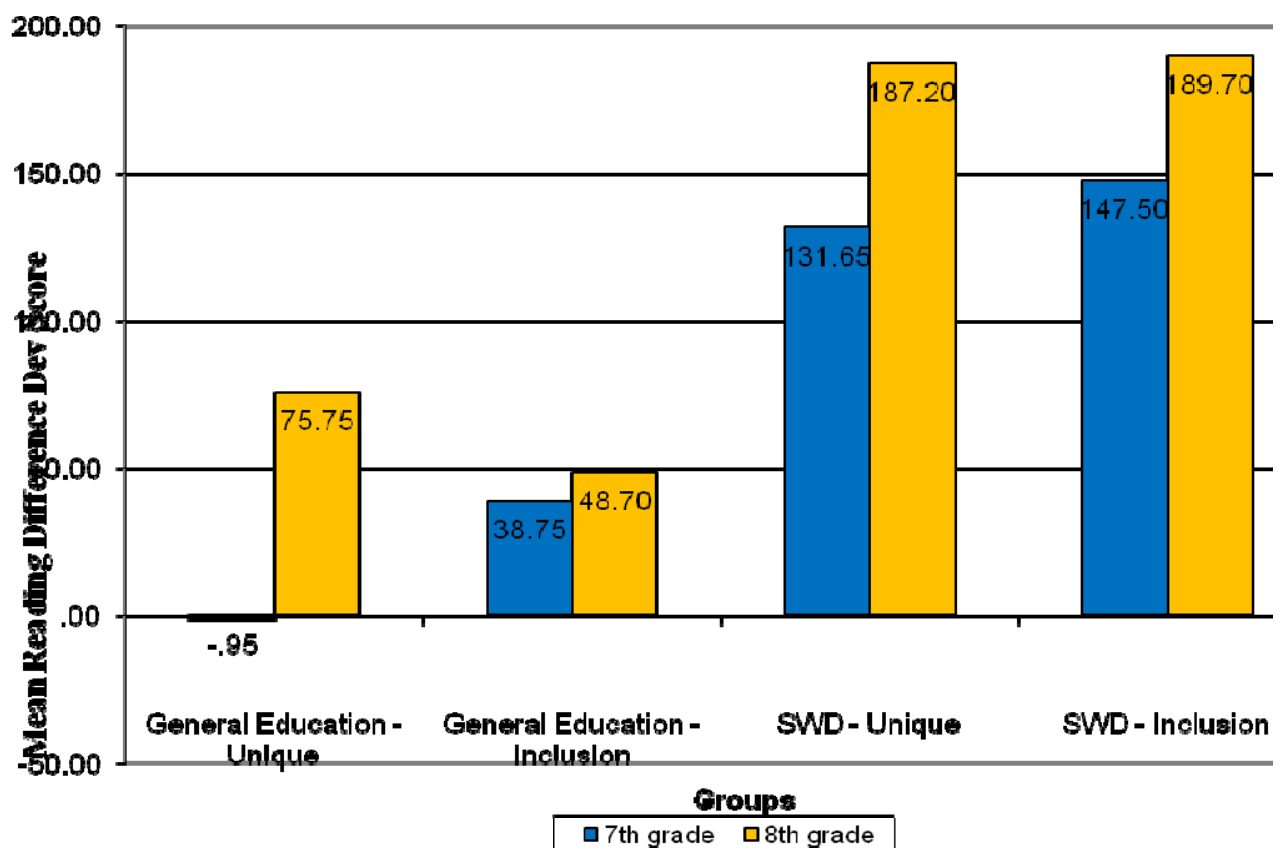


Table 15

Descriptive Statistics for Reading Developmental Scores

\begin{tabular}{|c|c|c|c|c|c|}
\hline Inclusion & Grade & Disability & Mean & Std. Deviation & $\mathrm{N}$ \\
\hline \multirow[t]{9}{*}{ No } & Grade 7 & Non-Disabled & -.95 & 171.100 & 20 \\
\hline & & SWD & 131.65 & 259.771 & 20 \\
\hline & & Total & 65.35 & 227.258 & 40 \\
\hline & Grade 8 & Non-Disabled & 75.75 & 253.879 & 20 \\
\hline & & SWD & 187.20 & 199.627 & 20 \\
\hline & & Total & 131.48 & 232.380 & 40 \\
\hline & Total & Non-Disabled & 37.40 & 217.190 & 40 \\
\hline & & SWD & 159.42 & 230.394 & 40 \\
\hline & & Total & 98.41 & 230.785 & 80 \\
\hline \multirow[t]{9}{*}{ Yes } & Grade 7 & Non-Disabled & 38.75 & 188.509 & 20 \\
\hline & & SWD & 147.05 & 335.528 & 20 \\
\hline & & Total & 92.90 & 274.164 & 40 \\
\hline & Grade 8 & Non-Disabled & 48.70 & 231.607 & 20 \\
\hline & & SWD & 189.70 & 354.152 & 20 \\
\hline & & Total & 119.20 & 303.866 & 40 \\
\hline & Total & Non-Disabled & 43.72 & 208.496 & 40 \\
\hline & & SWD & 168.38 & 341.199 & 40 \\
\hline & & Total & 106.05 & 287.863 & 80 \\
\hline \multirow[t]{9}{*}{ Total } & Grade 7 & Non-Disabled & 18.90 & 178.826 & 40 \\
\hline & & SWD & 139.35 & 296.281 & 40 \\
\hline & & Total & 79.12 & 250.590 & 80 \\
\hline & Grade 8 & Non-Disabled & 62.23 & 240.254 & 40 \\
\hline & & SWD & 188.45 & 283.760 & 40 \\
\hline & & Total & 125.34 & 268.848 & 80 \\
\hline & Total & Non-Disabled & 40.56 & 211.560 & 80 \\
\hline & & SWD & 163.90 & 289.303 & 80 \\
\hline & & Total & 102.23 & 260.096 & 160 \\
\hline
\end{tabular}


Table summaries and related analyses of findings. The mean score for SWD in a non-inclusive setting in math was 21.80 with a standard deviation of 273.92 and a mean of 96.48 with a standard deviation of 242.64 for SWD in a co-taught inclusion setting. The mean score for students without disabilities in a non-inclusive setting in math was 66.60 with a standard deviation of 187.68 . For students without disabilities in a co-taught inclusive setting in math, the mean was 96.48 with a standard deviation of 242.638. In reading, the mean for SWD in a non-inclusive setting was 159.42 with a standard deviation of 230.40. Students with disabilities in a co-taught inclusive setting had a mean of 168.38 and a standard deviation of 341.20 . The mean for students without disabilities in a non-inclusive setting in reading was 37.40 with a standard deviation of 217.190 and a mean of 43.72 with a standard deviation of 208.50 for students in an inclusive setting.

Tables 16 and 17 contain the independent variables and show the statistical significance of each. The level of significance for the procedure was 0.05. As shown, grade level and disability accounted for a significant difference in predicting mean performance level changes in math with an obtained p-value of 0.008 , which is less than the alpha level of 0.05 . The results of this analysis on reading difference developmental scores indicates a significant difference at alpha level 0.05 that performance varies as a result of disability with an obtained p-value of 0.03 . As one of the main goals of this study was to explore relationships among educational placement and performance levels, it is important to note that educational setting (inclusion or non-inclusion), disability (SWD or students without disability), and grade level ( $7^{\text {th }}$ grade or $8^{\text {th }}$ grade) accounted for significant variance for students in math with an obtained $\mathrm{p}$-value of 0.049 at alpha level 0.05. However, educational setting (inclusion or non-inclusion) did not account for 
significant variance for SWD or students without disabilities in grades seven or eight in Reading when statistically controlling other variables.

Table 16

Tests of Between Subject Effects for Math

\begin{tabular}{lrrrrr}
\hline Source & $\begin{array}{c}\text { Type III Sum } \\
\text { of Squares }\end{array}$ & df & Mean Square & \multicolumn{1}{c}{ F } & \multicolumn{1}{c}{ Sig. } \\
\hline Corrected Model & $646396.675^{\mathrm{a}}$ & 7 & 92342.382 & 2.007 & .058 \\
Intercept & 577681.225 & 1 & 577681.225 & 12.555 & .001 \\
INCLUSION & 40386.025 & 1 & 40386.025 & .878 & .350 \\
EIGTHGRADE & 10400.625 & 1 & 10400.625 & .226 & .635 \\
Disability & 144.400 & 1 & 144.400 & .003 & .955 \\
INCLUSION * & 5593.225 & 1 & 5593.225 & .122 & .728 \\
EIGTHGRADE & 73616.400 & 1 & 73616.400 & 1.600 & .208 \\
INCLUSION * & & & & & \\
Disability & 335622.400 & 1 & 335622.400 & 7.294 & .008 \\
EIGTHGRADE * & & & & & \\
Disability & 180633.600 & 1 & 180633.600 & 3.926 & .049 \\
INCLUSION * & & & & & \\
EIGTHGRADE * & 8218080.000 & 160 & & & \\
Disability & 7640398.775 & 159 & & & \\
Total & & & & & \\
Corrected Total & & & & & \\
\hline
\end{tabular}

a. $\mathrm{R}$ Squared $=.085($ Adjusted R Squared $=.042)$ 
Table 17

Tests of Between Subject Effects for Reading

\begin{tabular}{|c|c|c|c|c|c|}
\hline Source & $\begin{array}{l}\text { Type III Sum } \\
\text { of Squares }\end{array}$ & df & Mean Square & $\mathrm{F}$ & Sig. \\
\hline Corrected Model & $719754.894^{\mathrm{a}}$ & 7 & 102822.128 & 1.557 & .152 \\
\hline Intercept & 1672196.556 & 1 & 1672196.556 & 25.325 & .000 \\
\hline INCLUSION & 2333.256 & 1 & 2333.256 & .035 & .851 \\
\hline EIGTHGRADE & 85423.806 & 1 & 85423.806 & 1.294 & .257 \\
\hline Disability & 608485.556 & 1 & 608485.556 & 9.215 & .003 \\
\hline $\begin{array}{l}\text { INCLUSION * } \\
\text { EIGTHGRADE }\end{array}$ & 15860.306 & 1 & 15860.306 & .240 & .625 \\
\hline $\begin{array}{l}\text { INCLUSION * } \\
\text { Disability }\end{array}$ & 68.906 & 1 & 68.906 & .001 & .974 \\
\hline $\begin{array}{l}\text { EIGTHGRADE * } \\
\text { Disability }\end{array}$ & 333.506 & 1 & 333.506 & .005 & .943 \\
\hline $\begin{array}{l}\text { INCLUSION * } \\
\text { EIGTHGRADE * } \\
\text { Disability }\end{array}$ & 7249.556 & 1 & 7249.556 & .110 & .741 \\
\hline Total & $1.243 \mathrm{E} 7$ & 160 & & & \\
\hline Corrected Total & $1.076 \mathrm{E} 7$ & 159 & & & \\
\hline
\end{tabular}

a. R Squared $=.067$ (Adjusted R Squared $=.024$ )

\section{Strand II}

For the qualitative strand, the participants consisted of a heterogeneous population of 16 students, (8 students with SLD and 8 non-disabled peers), and 4 teachers, (two general education and two special education teachers), in co-taught inclusive classrooms, general education classrooms, and resource room classrooms for reading and math. Students represented the highest and lowest average on achievement changes for the 2008-2009 FCAT. Students and teachers were assigned pseudonyms in order to retain their confidentiality. Identifiers were not reused as a student may have participated in two of the observations (i.e., student may be a high performer, as indicated by developmental 
score change in reading and a low performer, as indicated by developmental score change in math). As such, a student may have two pseudonyms, one for each setting. However, this was not the case for this study.

The following narrative details the witnessed 16 observation periods of studentteacher interactions in the various educational settings. All observations were conducted in the students' normal learning environment and lasted approximately 30 minutes per student. In order to gain information that focused on the students and their interactions with the teachers within the classroom, the special education teachers assigned to the cotaught inclusion classroom and the resource classroom for reading and math respectively were the same as was the general education teacher assigned to the co-taught inclusion classroom and the general education classroom for reading and math respectively to avoid additional influences such as style of teaching. As such, only four teachers and their interactions with the 16 identified students were observed.

The observation process consisted of three stages: (a) documenting the lessons, (b) coding the material, and (c) analyzing the coded information. As suggested by Patton (2000) field notes were used to document interactions between teachers and students in a natural setting. Notes from the log were transcribed within a 24-hour period after each observation to capture as much detailed information as possible.

Interactive behaviors observed between students and teachers were categorized according to source: (1) teacher-initiated - student responses directly induced by, and addressed to, the teacher (including all kinds of student responses: academic and discipline); and (2) student-initiated - spontaneous student statements addressed to the teacher (academic questions and, mainly, calling out of turn). Figure 3 depicts these 
meta-themes that became evident across co-taught inclusive classrooms, general education classrooms, and resource room classrooms for reading and math for teachers and students.

Figure 3

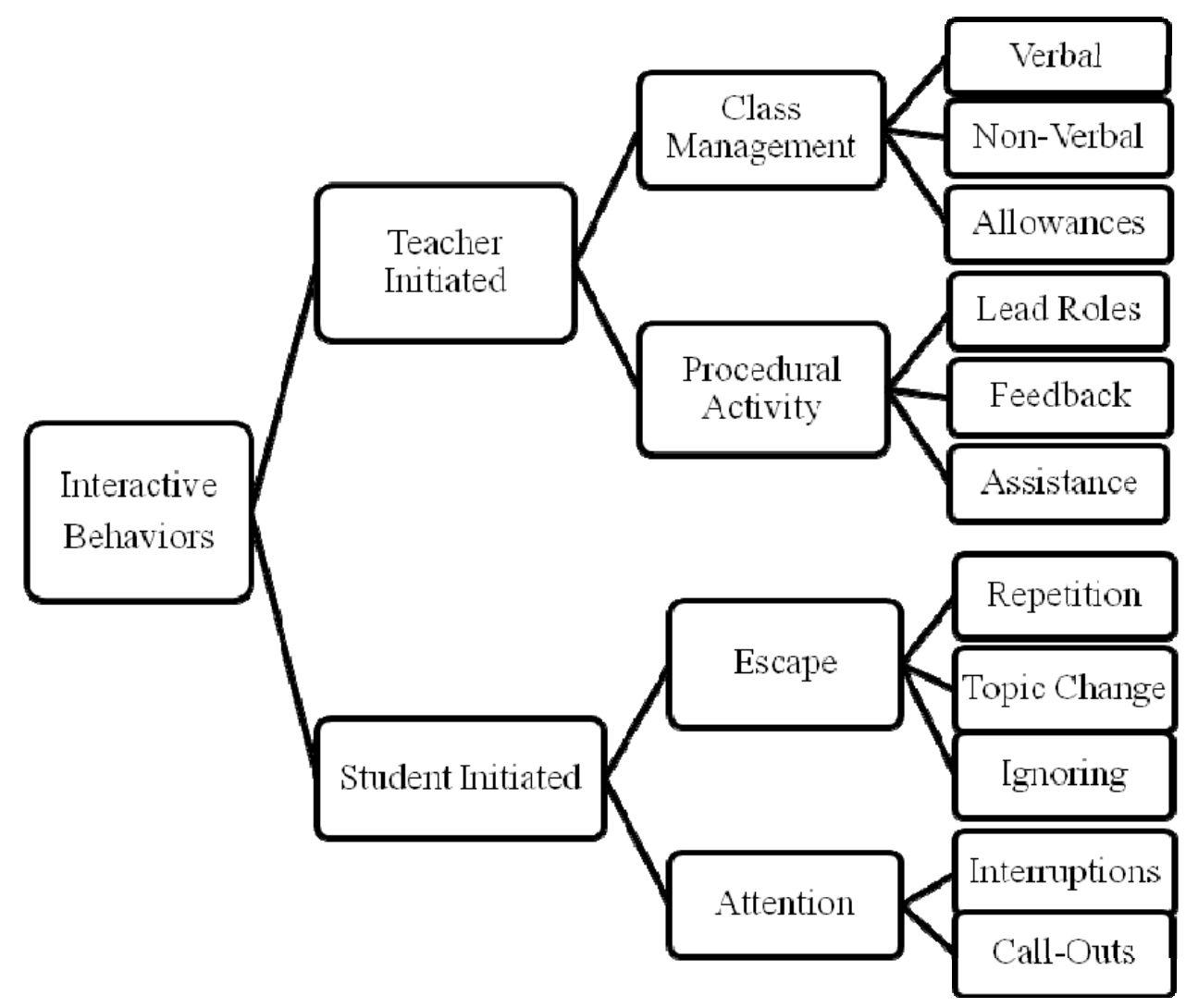

Observed Interactive Behaviors between Students and Teachers

\section{Teacher Initiated Interactions}

As per the observations, most teachers divide class time in two parts: class management and procedural activity. Class management, in the observed classrooms encompassed students' violation of school rules, and procedural activity with the 
organization of classroom activity according to the lesson routine. These categories were subdivided by observed behavioral trends. The four classroom settings manifested differences in student-teacher interactions. The personality of each class influenced the whole spectrum of teachers' school role behaviors as did the distribution of said roles within the classroom setting as related to inclusion.

Class management. Teacher behaviors regarding student behaviors were considered one category and subcategorized as either: (a) Verbal, (b) Non-Verbal, or (c) Allowances.

Verbal. The Verbal subclass included voice inflection and threats. Threats referred to "if-then" statements of loss of privileges or consequences at a later time. For example, Mr. Garcia maintained the same demeanor throughout settings, presenting class material within the class setting and reminding students of the weighted grade of the assignment. To Claudia, Mr. Garcia stated, “If you don’t complete your assignment, you will get an F."

Within the general education setting, when Mr. Sanchez asked Oscar to read, Oscar replied, "I don't know what page we are on Mister. Can you go on to the next person?" Mr. Sanchez guided Oscar stating, "We are on page 561, paragraph 2, line 3." When students did not readily volunteer, as was the case with Carlos, a low performing student, Ms. Rodriguez called in him and coaxed him through the problem's solution. Carlos sat with his back towards the projector where Ms. Rodriguez had the lesson displayed. As such, most of the interactions between Carlos and Ms. Rodriguez dealt with class management for procedural purposes. "Carlos, turn around so you can see this," was repeated five times within a 20-minute span. Carlos would smile and turn 
his body slightly. As soon as Ms. Rodriguez resumed speaking, Carlos would turn his body again.

Amidst a class discussion led by Ms. Martinez, Mr. Sanchez initiated a conversation with Johnny, a high performer, by asking him if he would you like to answer the question. Johnny replied, "Not really," and bowed his head.

In the resource setting, students were asked to turn to page 560 in their textbooks. Ms. Martinez immediately began reading. After the first paragraph, Ms. Martinez called on Julio to read as his book was not yet opened. "While we wait for Julio, Mario, please read."

Non-Verbal. In the resource setting, Julio, after a verbal admonishment, got angry, pouted, and withdrew from the rest of the class choosing to sit an area of the room away from others. He sat down, slumped in his chair, put his head down and refused to participate in the class activity. Ms. Martinez, who was walking around the room leading the discussion, walked over to where the students kept their composition books, picked Julio's out, placed it on Julio's desk, and patted him on the back to gain his attention.

Within the inclusion setting, while still carrying a discussion with another student, Ms. Martinez walked to stand next to Johnny, placing her hand on Johnny's shoulder. Ms. Martinez gave a silent nod to Mr. Sanchez communicating that Johnny had completed his assignment and was on-task. She remained by Johnny's seat for a few more moments. Mr. Sanchez remained by the side of the room throughout the incident.

Throughout the observations, two teachers were observed using their hands to emphasize a point. Ms. Rodriguez used hand gestures to redirect Christopher to his seat 
and Ms. Rodriguez to gain Jorge's attention by clapping her hands before the onset of a new task.

Allowances. Mr. Garcia stated that he would call on people who had their hands raised. Several hands immediately went up, waving in the air. The students were not supposed to shout out the answer. Sometimes, however, a student said the answer before being called on. Sometimes Mr. Garcia ignored this, at other times he scolded the student. Nancy, a low performing student, was one of the students Mr. Garcia noticed when she called out; Victor was not. Victor, a high performing student, tended to call out an answer when no one else responded. It almost seemed as if a private conversation between $\mathrm{Mr}$. Garcia and Victor enfolded.

Mario is a low performing student who sat next to Ms. Martinez's desk, creating his own desk with a chair and the border of Ms. Martinez's desk rather than sitting in a student desk. He continuously asked if he could help by erasing the board, grading papers even though class had not begun. Jose has a birthmark which covers his right hand, of which he appears to be very conscious. He sat in the row closest to the wall so that his right hand is obscured. Additionally, participation, when it refers to hand raises was made with his left hand. The student next to him was very quick to respond. At first, Jose reacted to the challenge, much like a Jeopardy game; then he stopped. When the teacher did not correct answers stated aloud, Jose was quick to respond. His calling-out of the answer seemed more a purposeful class strategy than an oversight. However, this was not the perception by the other students as evident by their complaints as to class procedures, specifically, "That's not fair. I raised my hand." 
Procedural activity. Procedural Activities include common instructional tasks such as giving information and asking questions. Within this category, subcategories include: (a) Lead Roles, (b) Feedback, and (c) Assistance.

Lead Roles. The behaviors emitted by the teachers varied depending on the setting. When functioning in academic and managerial roles, Mr. Sanchez's interactions with students greatly differed within the inclusion setting. Within the general education setting, Mr. Sanchez walked to the front of the classroom and began a whole class discussion based on a posted prompt by reading the prompt aloud, immediately initiating a response from Oscar, a low performing student. "I don't know what I would do. I mean, that situation would never happen.” Mr. Sanchez continued cueing a response from Oscar through questions that eventually led to a detailed answer. When in a co-taught session, Mr. Sanchez allowed Ms. Martinez to lead the discussion, standing to the side of the classroom.

In the math general education setting, 22 students sat in clusters of three or four as Mr. Garcia went over how to solve an inequality. The class completed this together, the teacher at the board, the students on sheets of paper in front of them. Within the inclusion setting, Ms. Rodriguez worked the problem on the board, detailing steps and asking students to volunteer the next operation.

In the reading inclusion class, Mr. Sanchez introduced the next lesson, but it was Ms. Martinez who asked for a volunteer to read the prompt and initiated a class discussion by providing her personal response. This behavior generalized into the resource room setting where Ms. Martinez read the initial prompt aloud and gave her personal anecdote while walking around the class and perusing each student's response. 
Feedback. "Thank you for taking out the book so quickly, David," Ms. Martinez said. David, a low performing student, asked to read the first section aloud and participated orally in the class lesson responding to Ms. Martinez's questions. When asked to go to the board and answer a question, despite having not completed the assignment, Melissa had no difficulties in doing so earning Melissa a "Good job," from Ms. Rodriguez.

Assistance. Within the Math inclusion setting, Ms. Rodriguez handed out a quiz. Jonathan, a high performing student, stated, “I can't take the quiz because I was absent yesterday."

Mr. Garcia, from across the room explained that Jonathan was present for the material as it was covered throughout the week. "Still, I wasn't here yesterday, so I don't know how to do it," insisted Jonathan, looking for Ms. Rodriguez across the room. Upon eye-contact, Ms. Rodriguez told him to, "Try your best. If you get stuck, let me know." Although Jonathan never requested assistance, Ms. Rodriguez went over to him and assisted him. Mr. Garcia made his rounds around the room, but never once stopped at Jonathan's desk.

Yet, this assistance was not apparent with Roxanna, a low performing student. The class period had Roxanna staring at Ms. Rodriguez and biting her nails. Ms. Rodriguez motioned Mr. Garcia towards Roxanna’s desk. Mr. Garcia was sitting on a stool by the classroom's podium, taking notes. "Roxanna, why aren't you working?" he asked. Roxanna stopped biting her nails and immediately began writing something on her paper. "Roxanna, did you understand the lesson?” asked Ms. Rodriguez as Roxanna packed her books into her bookbag. "No, not really," she stated as she looked towards the 
door. "Why didn't you say something to Mr. Garcia while I was teaching, or even to me?" Roxanna smiled shyly, but did not respond. Ms. Rodriguez shook her head.

\section{Student Initiated Interactions}

According to Cusick $(1992,1993)$, students are able to exert a tremendous amount of influence upon the teacher by choosing either to resist or to cooperate with the teacher. For example, students may decide whether to resist or to cooperate with the teacher depending upon the degree of compatibility between student and teacher goals. Student initiated interactions observed within the four classroom settings in respect to studentteacher interactions was relatively independent of situational factors and was motivated more by students' spontaneous comments to elicit attention or avoid a task due to difficulties of the activity(ies) or a lack of challenge on behalf of the student. Task avoidance included avoidance of attention. The trends of student behaviors were classified as: (a) escape and (b) attention, each with subcategories. It is important to note that the personality of each class again influenced the whole spectrum of student-teacher interactions and as such common behaviors were evident.

Escape. Avoidance behaviors seemed to have been developed by students to fool the teacher(s) into thinking that they understood the lesson, were completing their assignments, or not to call attention to themselves within the classroom setting. These behaviors were subcategorized into: (a) repetition, (b) topic change, and (c) ignoring.

Repetition. Students used excessive questioning to get the teachers to repeat instructions or directions. This was specifically seen in an interaction between Ms. Martinez and David, a low performing, general education student within an inclusion class. 
Ms Martinez: "I want everyone wearing green to read on the count of three. Ready, one, two..."

David: "Ms., I have green in my shoe, does that count?"

"No. I meant to say, if you have a green shirt on."

"A green school shirt? Because I have on a green undershirt."

"No, a green school uniform shirt. And, you do not have a green undershirt on."

"Oh, you're right."

The reading activity continued with similar student questions. Eventually, Ms. Martinez selects one student to read the passage.

In Math class, Claudia, a low performing SWD within an inclusion class, lined up all of her supplies perfectly on her desk. Mr. Garcia was walking around the room.

"Claudia, why haven't you begun to copy today's math prompt?"

"Which one?" asked Claudia.

"The prompt that is where it is always at," he points to the whiteboard where the word "Prompt" is clearly displayed.

"Would you like me to read it to you?" asked Ms. Rodriguez as she walked to Claudia's other side.

Claudia looked at Ms. Rodriguez, smiled, and read the prompt to her. Mr. Garcia walked away. Ms. Rodriguez also smiled and patted Claudia on the shoulder before commenting, "Ok, now start copying it and solving the problem?"

"Which problem?" asked Claudia as she continued to place pencils on the corner of her desk. 
Topic change. Students use topic changes in two ways: (a) by responding to questions with completely unrelated responses, and (b) by initiating topic changing questions. For example, the following two student responses by Nancy and Jorge demonstrate intentional attempts to change the topic.

When cued to answer a math problem on the board, Nancy asked Mr. Garcia if he liked her new glasses. She continued the conversation by stating where she had purchased the glasses and how much they cost. Other students responded by asking her questions. She stood at the whiteboard, marker in hand, but never completed the problem before Mr. Garcia asked her to take her seat and solved the problem for the class.

Another example of topic change occurred in the inclusion reading class with David. "So, let me get this straight. You want us to write an essay about the water shortage? There is no water shortage! I open the hose, and voila, water. Which is interesting, because shouldn't they restrict how many times I can open the hose? I mean is that possible? Is there really a Big Brother watching us? What do you think Mr. Sanchez?" A discussion between David, a low performing student, and Mr. Sanchez ensued where Mr. Sanchez attempted to get David to support his reasoning with stronger details regarding the water shortage. The discussion turned into a conversation about how much water a person should drink throughout the day, an evident deviation from the lesson.

In both of the above cases, the change of topic catches the teacher off guard and changes the content of their instructional conversation. In both cases, after making their topic changing statements, other students in the classroom reinforce the topic change. 
Another way in which students change the topic from instructional conversation is by initiating their own topic changing questions. For example, while reading the selected text, Mr. Sanchez asked the class to describe the King. Jose calls-out, "Reign. Isn't that a kingdom? I learned about that in Social Studies class. Who else has Ms. Smith for Social Studies?"

A similar scenario occurred in the math inclusion class where Claudia, a low performing SWD, interrupted Ms. Rodriguez's explanation on how to solve ratios by commenting on the shadows cast by the projector on the wall. "Ms., it looks like you super-sized yourself because of the projector." That led to a discussion among the students on their favorite "Super-Size" food items.

Oscar took his time searching for the page. "Mister, go on to the next person. I'll read the next paragraph.” Mr. Sanchez did just that. Oscar then proceeded to ask questions about what was read. His book remained closed. He never read aloud avoiding the task.

Ignoring. Ignoring refers to behaviors where students divert their attention to other objects. For example, Melissa, a high performing student within the math resource setting, appeared busily at work. When she turned toward the student to her right, it became apparent that rather than taking notes or completing the assignment, Melissa had made a "cootie catcher." A cootie-catcher is a paper gizmo that opens and closes in your hand with the assistance of four fingers revealing messages.

Other students like Isabella play with their pens, clicking it open and closed, the only sound emitted by her throughout the class period. For, despite her physical appearance, which bordered on following school rules with her two toned hair color and 
bright nail polish, Isabella remained quiet never once raising her hand or making a comment to any discussion point. She completed her assignment and turned it in at the proper time to the teacher.

Attention. Some students appeared to be very smart as evidenced by their questions and inferences within the class, but to impress their peers, they spent most of the time in class joking around and causing disruptions, initiating interactions before the end of class to distract from their lack of work. These behaviors were classified as interruptions.

Interruptions. Students use interruption including interrupting instructional explanations to break in on teacher-directed activities. Students interrupt a lesson upon the first available pause or break in the lesson. For example, after discussing the daily prompt, Mr. Sanchez asked the class to take out the literature textbooks from underneath their desks. Oscar took this break to ask, "What are we going to do after this?" Mr. Sanchez commented. "Oscar, don't worry about that, let's finish this first." Oscar continued to inquire about the next activity to which Mr. Sanchez eventually answered with a detailed description.

Students were all working independently on a reading comprehension selection while Ms. Martinez walked around the class assisting individual students. As she approached Christopher's desk, he raised his hand. Christopher, a low functioning SWD within an inclusion reading class, walked towards Ms. Martinez before she made it to his desk. There was no textbook in his hand, no handout, and no pencil. "What's the question?” Ms. Martinez asked, to which Christopher replied, “Oh, I forgot.” The entire class began to laugh. Ms. Martinez asked to see the work Christopher had done 
proceeding to his desk. Christopher stepped in front of her, smiled, looked around the class, and asked if he could go to the bathroom. Ms. Martinez corrected Christopher replacing "can" with "may" almost automatically as she had moved on to peruse another student's work. Christopher repeated the question, utilizing the correct word as he walked towards the door; the answer to his question a silent/understood "Yes." Neither Ms. Martinez nor Mr. Sanchez ever saw his work, or lack thereof.

When assigned the independent work, Jorge immediately stood up to sharpen his pencil. The pencil sharpener made a grinding noise and for three minutes before Ms. Rodriguez asked what he was doing. Jorge replied that he was trying to sharpen his pencil. Ms. Rodriguez stated that the pencil was sharp enough and asked Jorge to return to his seat and his assignment. As he returned to his desk, Jorge paused to show Ms. Rodriguez and Mr. Garcia his pencil. When at his desk, Jorge searched through his book bag. "What are you doing?" asked Ms. Rodriguez. "Searching for another pencil or lead," said Jorge. The bell rang before Jorge found an adequate writing tool. However, Jorge was an avid participant throughout the oral discussion of the lesson, volunteering answers.

Roxanna, a low performing general education student within an inclusion class, used a similar tactic. "I can't find my pencil," commented Roxanna "Grab one from my desk," said Ms. Rodriguez.

"Do you have lead?" asked Roxanna.

“No, but I have a pencil you can use," said Ms. Rodriguez.

"But, I want lead."

"Why do you need lead if you can’t find your pencil?" 
Roxanna smiled.

As Ms. Martinez walked away from Julio after garnishing attention on him due to his lack of participation in a class activity, Julio looked up from his position of his head down on his desk, opened up his book, and sat up. While he did not seem interested in completing his work, Julio quickly responded to a female student's comment, "We have to conserve water." That's correct..." said by Ms. Martinez was interrupted by Julio who loudly made the side comment, "Yeah, we should shower together."

Call-outs. Call-outs are sometimes viewed as student eagerness to participate in the class discussion. However, they can be distracting and detouring to others. For example, Mario's hand was raised to read as soon as the directions to do so were given. Julio who sat in the middle of the class stated aloud that he was ready to and wanted to read. He was told that he would be called to read next. As soon as Ms. Martinez asked a question, Julio raised his hand while simultaneously calling out the answer. When Mario raised his hand to answer the question, Julio looked over at him with an intimidating stare and voiced, "Put your hand down, before I whoop your ass!" Mario did. When Ms. Martinez picked Mario, ignoring Julio, Julio called-out the answer, not losing eye contact with Mario. Ms. Martinez continued to ignore Julio. However, Mario did not reply. Eventually, Julio stated the correct answer and the lesson resumed with Julio reading aloud.

In the general education math class, Nancy called-out, "You multiply. No, you divide," when Mr. Garcia asked what operation was defined by the word "difference." Mr. Garcia directed her to "Think again," and called on another student to answer the 
question. When Mr. Garcia asked the class how to find the area, Nancy again called out, "You multiply. No, you divide."

"Look at your reference sheet before you answer and wait to be called on," stated Mr. Garcia. He called on another student whose hand was raised. "You multiply base times height."

“That's what I said," called Nancy.

\section{Summary of Results}

The purpose of this study was to examine classroom placement (inclusive versus non-inclusive) relative to the academic achievement of urban low socio-economic Hispanic students with disabilities and their non-disabled peers in secondary content area classrooms. The study compared performance levels of four middle school student subgroups (students with disabilities in inclusive settings, students without disabilities in inclusive settings, students with disabilities in resource settings, and student without disabilities in general education settings) each in their respective placements for two consecutive years, exploring existing practices within authentic settings. All students were selected based on similar socio-economic status, ethnicity, disability status, school attendance, and language dominance.

Participants for the quantitative strand of this study included 160 Hispanic middle school students from two participating schools. Students were assigned to groups based upon their educational placement and status (i.e., students with disabilities, students without disabilities). Educational placement and status were independent variables in this 
study. Groups consisted of (a) 10 students with SLD in an inclusion setting, (b) 10 students without disabilities in an inclusion setting, (c) 10 students with SLD in a resource setting, and (d) 10 students without a disability in a general education setting for each school site per grade level (seventh and eighth grades) totaling 80 students per site and a combined 160 student participants.

Strand I explored whether placement (inclusive versus non-inclusive classrooms) affected achievement change for Hispanic middle school students with and without specific learning disabilities in reading and math as measured by change in the mean development score in the state assessment. Data collected reveled that there was significant difference in placement, grade level, and disability in student achievement in predicting the mean performance level changes in math. Data collected also revealed that performance varies as a result of disability in mean performance level changes in reading.

Participants for Strand II included a heterogeneous population of 16 eighth grade students, 8 students with SLD and 8 non-disabled peers, in co-taught inclusive classrooms, general education classrooms, and resource room classrooms for reading and math, representing the highest and lowest average on achievement changes for the 20082009 FCAT. Based on the qualitative techniques of observation, student-teacher interactions were explored. The data were organized and then categorized with emphasis on the establishment of themes (Bogdan \& Biklen, 2007) that described interactive behaviors observable between student and teacher(s) within different educational placements for Hispanic middle school students with and without specific learning disabilities. The meta-themes that emerged were: (a) teacher-initiated and (b) studentinitiated. 


\section{CHAPTER V}

\section{DISCUSSION AND CONCLUSIONS}

The achievement of all learners is the cornerstone of educational accountability. Although students with disabilities have traditionally lagged behind their non-disabled peers, the mandates of NCLB require students with disabilities to perform at the same level as other students on reading and mathematics state assessments to meet the Adequate Yearly Progress targets.

As per Bielinski and Ysseldke (2000), exclusive delivery methods have been associated with significant achievement gaps. In light of this, a serious consideration of educational services delivered through a more inclusive system is warranted. Inclusion is a promising practice in the field of special education that ensures that students with disabilities are served in general education classes with non-disabled peers and are provided with instructional support to access curricular content.

Co-teaching is among the service delivery models implemented in the general education classroom in order to implement inclusion (Rea \& Connell, 2005; Weiss \& Lloyd, 2002). General education and special education teachers are charged with structuring the co-teach inclusion classroom around tasks that emphasize learning mastery for all students. There must be positive outcomes for general education students in co-taught inclusion settings as well as for SWD.

This study specifically examined classroom placement (inclusive versus noninclusive) relative to the academic performance of Hispanic students with learning disabilities and their non-disabled peers in secondary content area classrooms. The study utilized data from the quantitative strand, the first strand, to guide the selection of 
students for the qualitative strand, the second strand (Tashakkori \& Newman, in press).

Statistical investigations of the relations between placement, grade level, and mean change in FCAT test scores in reading and mathematics from the 2008-2009 to 20092010 administration were conducted.

In Strand I, two (reading and math), Three-Way Mixed Analysis of Variance (ANOVAs) were used. The factors were placement (inclusion or non-inclusive), grade level (seventh or eighth grade), and SLD (yes or no). The dependent variable for the study was the FCAT mean learning change in reading and math respectively. The ANOVA compared the amount of between group variance on the students' mean change scores on the 2008-2009 FCAT administration from the 2009-2010 FCAT administration in the areas of reading and mathematics for each group of students (SWD or students without disabilities), for each grade, and by grade level interactions.

In Strand II, case study methodology was used to interpret student interactions with teachers within a real-life context (Yin, 2003). The case study methodology identified factors, such as body language, level of focus on the learning activity, level of verbal participation, and the level of completion and/or engagement in a task, that may contribute to improved student achievement within the real-life context of a selected middle school and school district. In addition, the case study methodology allowed the researcher to present rich descriptions of the setting and the students' interactions (Bogdan \& Biklen, 2007), specifically from classroom observations, that may lead to more in-depth information about specific behaviors that occur in each placement. Information may explain noted differences in learning gains for students with and without 
disabilities. Data for the study were obtained from two major sources: an extant database provided by the district and classroom observations.

For the quantitative strand, descriptive and inferential statistics were utilized. The following calculations examined the quantitative research question of this study:

1. $t$ - tests or chi-square analyses on student demographic data of the groups in terms of their disability/non-disability status and grade level.

2. The mean achievement change score for Hispanic middle school students with and without specific learning disabilities in specific educational program placements (inclusive versus non-inclusive classrooms) in reading and math were analyzed using two, Three-Way Mixed ANOVAs.

Statistically significant differences were not observed among students without disabilities in general education classes and students without disabilities in co-taught inclusion classes for math. Significant differences were found among SWD and students without disabilities in reading. Significant differences were also not observed among SWD in co-taught inclusion classes as compared to SWD in resource room settings for reading and math. However, statistical differences were found among grade levels in math. Although there are no directly comparable previous studies of achievement based on state assessments on reading and math co-taught classes versus non-inclusion settings for Hispanic middle school students with and without learning disabilities, the findings of this study do parallel the results of those previous studies which are roughly related.

For example, many scholars (Rea, McLaughlin, \& Walther-Thomas, 2002; Strieker \& Logan, 2001) found academic gains associated with inclusive practices, this study did not. Differences may be attributed to a lack of variance in teacher thus teaching 
style, The findings of this study are consistent however, with a similar study of mathematics and reading achievement conducted by Redmon (2007) in which she examined whether or not the inclusive classroom improved the achievement scores of elementary students with disabilities on state assessments of reading and mathematics across a 3 year period. Redmon did not find a statistically significant difference between students educated in inclusive settings and students educated in resource settings. The findings of this study also parallel the results of McDonnell and colleagues (2003), Haseldon (2004), and Murawski (2006).

More specifically, in an experimental study, McDonnell and colleagues found that there were no significant differences among students with disabilities who were enrolled in inclusive classroom settings as compared to students without disabilities within a general classroom setting. Similarly, in a quantitative study, Haseldon (2004) found no statistically significant differences in passing rates among the full mix of students in four settings, including one co-taught class and two general education classes. Murawski (2006) found no significant differences in academic outcomes for reading assessments for SWD in the co-taught environment as compared to SWD in the resource room. Additionally, the findings of this study are also consistent with an inclusion study (Beam, 2005) which examined the relationship between inclusion and pullout special education programs for special education students with learning disabilities on reading and mathematics scores achievement. As in the previous studies, differences in the present study were not evident between the two models.

Mixed findings considering the body of research suggest that further study is needed before conclusions can be drawn between inclusion and achievement. A number 
of factors may have accounted for the lack of significant difference in the present study including the amount of and quality of professional development provided to staff. The latter may have manifested itself onto the observed interactive behaviors within the various classroom settings.

Finn (1989) described participation as having multiple levels. At the first level, students meet minimal requirements to pay attention, be prepared, and respond to teachers' directives and questions. It is this level that most closely matches the level of interactions observed in this study, specifically teacher-initiated interactions within the category of Class Management where the teachers observed in this study utilized verbal and non-verbal cues to gain and/or maintain student attention. These interactions were most apparent with low performing students and the special education teachers. For example, both Jorge and Roxanna were verbally re-directed when they demonstrated offtask behaviors, specifically searching for a pencil when assigned an independent task. On a second level of participation, students did more than what was required, initiated questions on their own, and were enthusiastic about learning, behaviors exhibited in this study by Mario. As such, student-teacher interactions involved a great continuum of behaviors.

Studies such as Marks (2000) and McDermott, Mordell, and Stolzfus (2001) show that students become more disengaged from school as they progress from elementary to middle to high school. It is not coincidental that the focus on standardized testing as an indicator of student performance is emphasized as students progress through the school system affecting classroom instruction. This disengagement, referring to minimal interaction between students and teachers, is evident in this study with high performing 
students both with and without learning disabilities, contradicting Yair's (2000) study where he found that students with disabilities were less engaged in academic classes. This is evident with Isabella as well as Jose who needed to be prompted by the teacher to participate in class discussions. High performing students, both non-disabled and disabled, within this study displayed more attention seeking behaviors than their low performing peers as seen with Jonathan, Nancy, and Julio.

The above alienation may have been a result of the demands placed by the teacher in respect to standards tested on the standardized assessment. In most classes, when the teacher stated their demands as per the pacing guide established by the state for FCAT practice(s), the students responded with passivity, quiet, and an absence of participation as well as shrugs and shakes of the head. Students were disconnected and alienated from the learning process and resistant as evidenced by their behavior. In some classes, students put their heads in their desks and feigned sleep, or they talked with each other. Participation only came about reluctantly after the teachers expressed anger, sarcasm, and/or loud voices.

When referring to engagement or interaction as a method of escape by means of repetition or topic change, then Yair's (2000) study correlates with the findings of this study as $60 \%$ of low performing SWD used these strategies in the various settings as compared to $40 \%$ low performing general education students to alienate themselves from instruction.

Teacher support is associated highly with student engagement specifically tied to teacher-student interactions. Interaction with students is one form of teacher attention and orients individual students and groups to classroom practices. According to Sobel and 
Taylor (2006), by distributing their attention to various students based upon the students' needs, teachers are demonstrating respect for students' learning abilities. They recommend distributing teacher attention to all students, but strategically attending to the students who have special needs.

In a study conducted in 2002, Weiss and Lloyd defined the distribution of teacher attention, specifically the roles of special education teachers within a co-taught classroom as: (a) support provider, where the teacher did not participate in instruction, but monitored student behavior within the classroom; (b) separate classroom instruction, where the teacher was responsible for instructional delivery, monitoring, and assessment for a small group of students in a classroom separate from the original co-taught classroom; (c) segmental teaching, where the teacher provided a segment of the curriculum to the entire class; and (d) teaching as a team, where the two teachers delivered instruction as a team simultaneously monitoring students.

Scruggs et al. (2007) and Volonino and Zigmond (2007) have expressed concern that the special education teacher frequently assumes the role of assistant in the inclusion classroom, however, this study found that both special education teachers controlled more classroom communication than did the general education teachers, who were more influenced by the academically dominant students. Therefore, in the observed classrooms in this study, teacher assistance and expectations of conduct appeared to be related to levels of perceived academic competence.

With respect to explaining to students, in both co-taught and resource room classrooms, special education teachers explained new concepts at the board by reading text or presenting on an overhead, they provided feedback after student responses, gave 
steps and details of tasks, reviewed concepts, and assisted students at their desks while the general education teacher explained to the whole class. Instruction in the resource room seemed to have been broken down into smaller units, delivered at a slower pace allotting more time for classroom discussion, and individualized more. As such, this study did not correlate with the findings of Weiss and Lloyd (2002), as the roles of the teachers seemed to have been reversed with the special education teacher having more student-teacher interaction than the general education teacher. This behavior may be attributed to both special education teachers being highly qualified in the content area taught thus confident with the material.

Despite the potential benefits derived from a collaborative partnership, the actual practice of collaboration varies dramatically among teachers engaged in co-teaching partnerships (Treder, Morse, \& Ferron, 2000). It was observed in this study that the general education teacher was more often engaged in modeling, demonstrating, or lecturing to the class as a whole within the general education setting. Conversely, the special education teacher was more engaged in modeling, demonstrating, and lecturing within the co-taught inclusion classroom. Thus, based on the observations, the general education teacher took on the role of assistant. For when teachers were observed interacting with students in the inclusion classrooms, primarily special education teachers were seen frequently assisting individuals at their desks while the general education teacher was removed from the instructional dialogue.

Moreover, during the observation sessions in the resource settings, the special education teachers did not typically assign independent work. As a result, students were engaged in classroom dialogue or completing an assignment as a whole group. In $34 \%$ of 
teacher action intervals, the teacher asked at least one question, compared with $17 \%$ and $8 \%$ of intervals in the co-taught inclusion and general education setting observations respectively. Of these intervals in the resource setting, to involve the whole class, the teacher used prompts such as "Who else was going to say that?" and "Tell me if you

agree with. ..." Also, analyses of observation data indicated that the teacher involved the whole class more often during question-asking time and increased percent of intervals of positive statements.

In addition, Jones and Dindia's (2004) meta-analysis suggests that teachers initiated more negative interactions towards male students than female students. Even though gender was not a controlled variable in this study, findings support that male students were desisted more than female students, $67 \%$ compared to $33 \%$ of the total observed interactions.

\section{Limitations}

The results of this study are limited in their generalizability because all of the student participants and all of the teacher participants were Hispanic. Participants drawn from other cultures may reflect varying interactive attributes and behaviors by both students and teachers. Moreover, only standardized assessments, specifically FCAT scores were used to measure achievement, thus a lack of measurements of social benefits.

An additional limitation exists as a result of the exclusion of the participants in the study. The original focus was intended to be on observable interactive behaviors between students and teachers in various settings. Although observations took place throughout a three-month period, it is possible that observations over a longer period may have generated more varied perspectives about interactions. 


\section{Recommendations for Future Research}

Federal and state legislation have created explicit expectations for student performance and consequences for schools, teachers, and students that fail to meet expectations. These policy changes have raised the bar for all students and educators in America's public schools. As such, research into the achievements of students has a long tradition supporting the need for continued examination for improving the academic performance of students. Globally, two trends can be distinguished: firstly, analysis of individual characteristics of students, and secondly, research which concerns the context in which the education takes place. Both approaches have proved their value for the explanation of the achievements of students. This study provided a snapshot of the relationship between educational setting and the achievement of middle school Hispanic students with and without learning disabilities.

Inconsistent and mixed findings across the growing literature base suggest that inclusion will continue to be an area of focus in educational research. This study used a database and a limited number of field observations as the primary respondents; another method of gaining more information on the evidence of inclusive features versus other educative settings is to solicit responses from teams at the schools composed of general education and special education teachers, administrative personnel, and students.

Further studies are also recommended across grade levels and exceptionalities as well as in the content area of science. Although NCLB currently focuses on reading and mathematics achievement, recent regulations require that all states assess students in science one time in elementary school, one time in middle school, and one time in high school. At this point, these scores are not calculated into AYP requirements; however, 
mandated assessments may imply that science will be the next content area included in AYP calculations. If this is the case, it may be helpful to school divisions to replicate this study using science mean change scores.

Although standardized tests are designed to measure student progress on the state curriculum for federal accountability purposes, supplemental assessments should be used to measure higher-order conceptual understandings. A study utilizing these two forms of assessment would mitigate the concern that evaluation systems reward teaching to the test rather than students' grasp of key concepts and facts. Results would determine whether the level of year-to-year improvement on the state standardized assessment correlates with the level of year-to-year improvement on the supplemental assessments.

Due to the limitations of this study, further long-term studies of the effects of inclusion on the social aspect and perceptions of teachers, general education students, and students with disabilities should be conducted. It would be beneficial to include in a research study of this type such topics as discipline referrals, student perceptions, and student satisfaction.

Moreover, many of the specific behaviors found in the literature describe teachers and their relationships with younger children (Hamre et al., 2007; Rimm-Kaufman \& Pianta, 2000), but it is equally important to understand relationships between adolescents and their teachers. As such, characteristics which include social emotional support, classroom organization and behavior management, instructional support, and student outcomes should be examined for middle and high school students to understand how interactive behaviors influence academic outcomes. 
Addressing the behaviors of teachers and the impact such actions have on student achievement is difficult. A study by Jones, Evans, Byrd, and Campbell (2000) used analysis of videotaped lessons in order to introduce teachers to their own biased behavior. Requiring in-service programs to address gender bias in the classroom will make teachers more aware of their own behaviors. Research into this practice and its' effects is also recommended.

\section{Implications}

The value of this study is not only in its findings, but the implications for future findings. This study did not discern statistically significant relationships between classroom placement (inclusive versus non-inclusive) of four Hispanic middle school student subgroups (students with disabilities in inclusive settings, students without disabilities in inclusive settings, students with disabilities in resource settings, and student without disabilities in general education settings) and academic success as measured through standardized tests. As some school divisions are resistant to implementing a new program such as inclusion due to financial restraints and/or fear of student needs, this study does show that the model of inclusion is the provision of the LRE for some students with SLD and does not negatively impact other students who do not have SLD.

Educational practitioners need to re-examine co-teach programs, the co-teach models that they are using and the selection process and criteria for selection of both general education students and special education students for participation in co-teach settings. In view of the findings of this study, educational practitioners employing coteach as an inclusive structure should closely re-examine student academic achievement as a function of the co-teaching practice itself and variations within the practice of co- 
teaching. For instance, teacher roles should be carefully examined in respect to student achievement.

Additionally, educational practitioners should assess the process of placing general education students in inclusion classes. Administrators and counselors should actively plan with special education staffs in scheduling co-teach classes and the general education students that are placed in those classes. If there are certain criteria for a general education student to be placed in a co-teach class, the validity of the criteria should be evaluated as well.

Furthermore, collecting and evaluating data with a variety of assessments during the school year would provide ongoing information on the achievement of all students in co-teach classes. The method districts use to code general education students and students with disabilities in co-teach classes should be studied so assessment data can be collected and analyzed effectively and efficiently.

\section{Discussion Summary}

Student success depends in large part on the individual student needs. With regards to students with disabilities, the variety of student needs and responsibility to address those needs increases. This study represented an opportunity to research different models of instruction and student-teacher interactions for the Hispanic middle school student with and without specific learning disabilities. Okpala, Smith, Jones, and Ellis (2000) found that there exists a link between student demographics and student academic achievement.

There are no clear remedies for increasing the achievement of racial/ethical minority SLD to address the challenges set forth by NCLB. This study examined the 
relationship between educative placement and this important issue of achievement. Although a significant correlation could not be found between the two, there are clear suggestions that differences exist between achievement and student-teacher interactions. Better education requires expanding the knowledge and skills of teachers in order to engage students and create positive student-teacher interactions.

Interactions within this study focused more on class management and re-direction for procedural activity than open-ended discussions that promoted critical thinking. Further investigations are warranted to obtain clear models to employ so that all students, despite placement and disability, have positive changes in achievement and studentteacher interactions. 


\section{REFERENCES}

American Educational Research Association (2004). Journal of Educational and Behavioral Statistics, 29(1). Retrieved January 24, 2010, from http://www.aera.net/publications/?id=590.

Amrein, A.L. \& Berliner, D.C. (2002). The impact of high-stakes tests on student academic performance: An analysis of NAEP results in states with high-stakes tests and ACT, SAT, and AP Test results in states with high school graduation exams. Tempe, AZ: Education Policy Studies Laboratory, Arizona State University.

Amrein-Beardsley, A., \& Berliner, D. (2003, August). Re-analysis of NAEP math and scores in states with and without high-stakes tests: Response to Rosenshine. Education Policy Analysis Archives, 11(25),7-20 .

Andrews, J., Carnine, D., Coutinho, M., Edgar, E., Forness, S., Fuchs, L., Jordan, D., Kauffman, J., Patton, J., Rosell, J., Rueda, R., Schniller, E., Skritic, T., \& Wong, J. (2000). Bridging the special education divide. Remedial and Special Educatio, 21(5), 258-260, 267.

Artiles, A.J. (2003). Special education's changing identity: Paradoxes and dilemmas in view of culture and space. Harvard Educational Review, 73(2), 164-202.

Artiles, A.J., Rueda, R., Salazar, J., \& Higareda, I. (2005). Within group diversity in minority disproportionate representation. Exceptional Children, 71, 283-300.

Artiles, A.J., Trent, S.C., \& Palmer, J. (2004). Culturally diverse students in special education. In J.A. Banks \& C.A. Banks (Eds.) Handbook of research on multicultural education ( $2^{\text {nd }}$ ed.; pp. 716-735). San Francisco: Jossey-Bass.

Assessing Student Performance (2000). School Administrator, 7, 1-23.

Baldwin, M. K. (2003). Effects of co-teaching on student participation and math success on students with learning disabilities in the general education classroom. Dissertation Abstracts International, 42(02).

Barton, P. (2001). Raising achievement and reducing gaps: Reporting progress toward goals for academic achievement. Commissioned paper. Washington, DC: National Education Goals Panel.

Bateman, D. \& Bateman, F. (2002). What does a principal need to know about inclusion? Arlington, VA: ERIC Clearinghouse on Disabilities and Gifted Education. (ERIC Document Reproduction Service No. ED473828). 
Beam, A.P. (2005). The analysis of inclusion rates versus pullout at the elementary level as determined by selected variables. Ed.D. dissertation, The George Washington University, United States- District of Columbia, Retrieved November 7, 2010, from ProQuest Digital Dissertations database. (Publication No. AAT 3161573).

Bielinski, J. \& Ysseldyke, J.E. (2000). Interpreting trends in the performance of special education students (Technical Report 27). Minneapolis, MN: University of Minnesota, National Center on Educational Outcomes. Retrieved February 25, 2009, from http://education.umn.edu/NCEO/OnlinePubs/TechReport27.htm

Bogdan, R., \& Biklen, S. (2002). Qualitative research for education: An introduction to theories and methods ( $4^{\text {th }}$ ed.) Boston, MA; Allyn and Bacon.

Bowers, J. \& Figgers, M.S. (2003). A description of how teacher behaviors, school funding, and teacher training influence the inclusion of world music in middle school choral curricula. Retrieved on October 3, 2009, from http://etd.lib.fsu.edu

Carnoy, M., \& Loeb, S. (2002, Winter). Does external accountability affect student outcomes? A Cross-State Analysis. Educational Evaluation and Policy Analysis, 24 (4), 305-331.

Cawley, J., Hayden, S., Cade, e., \& Baker-Kroczynski, S. (2002). Including students with disabilities into the general education science classroom. Exceptional Children, 68(4), 423-425.

Council for Exceptional Children [CEC]. (2000). Bright futures for exceptional learners: Introduction-An action agenda to achieve quality conditions for teaching and learning. Reston, VA: Author.

Creswell, J.W., (2003). Research design: Qualitative, quantitative, and mixed methods approaches $\left(2^{\text {nd }}\right.$ ed). Thousand Oaks, CA: Sage

Daniel, L. \& King, D. (1997). Impact of inclusion on academic achievement, student behavior and self-esteem, and parental attitudes [Electronic version]. The Journal of Educational Research, 91(67).

Deere, D. and W. Strayer (2001). Putting schools to the test: School accountability, incentives and behavior. Working paper. Department of Economics, Texas A\&M University

Department of Accountability, Research, and Continuous Improvement (May, 2009). Data analysis for school improvement. School District of Lee County.

Dowson, M., \& McInerney, D.M., (2001). Psychological parameters of students' social and work avoidance goals: A qualitative investigation. Journal of Educational Psychology, 93(1), 35-42. 
Dyson, A., Farrell, P., Polat, F., Hutchenson, G., \& Gallanaugh, F. (2004). Inclusion and pupil achievement. Journal of Educational Research, 91(2), 67-80.

Erickson, K.I. (2000). The impact of inclusion: A comparison of reading and math achievement of general education middle school students in inclusive versus noninclusive settings. Dissertation Abstracts International, 61(3), 944A.

Federal Register, (1999).Census. Retrieved June 24, 2009, from http://www.gpoaccess.gov/fr/

Figlio, David N. and Getzler, Lawrence (2002). Accountability, ability and disability: gaming the system? Working paper. University of Florida.

Finegan, J.E. (2005). Teacher's perceptions of their experiences with including students with special needs in the general education classroom setting throughout public and private schools in Texas. College Station: TX: Texas A\&M University.

Florida Department of Education, (2001). FCAT Scores. Retrieved April 20, 2009 from http://fldoe.org

Florida Department of Education, (2002). FCAT Scores. Retrieved April 20, 2009 from http://fldoe.org

Florida Department of Education, (2004). Assessment and accountability briefing book by the Florida Department of Education. Retrieved July16, 2009, from http://fcat.fldoe.org/pdf/fcataabb.pdf

Florida Department of Education, (2006). FCAT Scores. Retrieved April 20, 2009 from http://schoolgrades.fldoe.org/

Florida Department of Education (n.d.a). Assessment and accountability briefing book. Retrieved March 21, 2008, from http://www.firn.edu/doe/sas/fcat/pdf/fcataabb.pdf

Florida Department of Education (n.d.a). Developmental scores. Retrieved March 21, 2008, from http://www.firn.edu/doe/sas/fcat/fcat_score/score_report.htm

Florida Department of Education (n.d.a) FCAT myths vs. facts. Retrieved March 21, 2008, from http://www.firn.edu/doe/sas/fcat/pdf/myths-facts.pdf

Food and Nutrition Service. (2007). School meals: Income eligibility guidelines.

Retrieved April 3, 2009, from http://www.fns.usda.gov/cnd/goverance/notices/iegs/iegs.htm

Fore, C., III, Hagan-Burke, S., Burke, M., Boon, R.T., Smith, S. (2008). Academic 
achievement and class placement in high school: Do students with learning disabilities achieve more in one class placement than another? Education \& Treatment of Children, 31(1), 55-72.

Fossey E, Harvey CA, McDermott F, Davidson L. (2002). Understanding and evaluating qualitative research. Australian and New Zealand Journal of Psychiatry, 36, 717732.

Friend, M., \& Cook, L, (2003). Interactions: Collaboration skills for school professionals ( $4^{\text {th }}$ ed.). Boston: Allyn \& Bacon.

Fusarelli, L.D. (2004). The potential impact of the No Child Left Behind Act on equity and diversity in American education. Educational Policy, 18(1), 71-94.

Gale, P. F. (2005). Performance of students with specific learning disabilities in co-taught and pullout models of education. Dissertation Abstracts International, 65(12).

Gall, M.D., Gall, J.P., \& Borg, W.R. (2003). Educational research: An introduction. Boston, MA: Allyn and Bacon.

Giacobbe, A.C., Livers, A.T., Thayer-Smith, R., \& Walther-Thomas, C. (2001). Raising the academic standards bar: What states are doing to measure the performance of students with disabilities. Journal of Disability Policy Study, 12, 10-17.

Gravetter, F., \& Wallnau, L. (2000). Statistics for the behavioral sciences. Belmont, CA: Wadsworth/Thompson Learning.

Gullant, D., \& Rutter, M. (2000). Measuring local public school effectiveness. Contemporary Education, 71(4), 29-33.

Hamre, B.K., \& Pianta, R.C. (2001). Early teacher-child relationships and the trajectory of children's school outcomes through eighth grade. Child Development, 72, 625638.

Hancock, V., \& Betts, F. (2002, April 1). Back to the future: Preparing learners for academic success in 2004. Learning and Leading with Technology, 29(7), 10-14.

Haney, W., (2000). The myth of the Texas miracle in education. Sociological Methods and Research, 2, 365-375.

Hanushek, E., \& Raymond, M. (2003). Improving educational quality: How best to evaluate our schools? Education Next, 3(3), 48-55.

Hargreaves, A. (2003). Teaching in the knowledge society: Education in the age of insecurity. New York: Teachers College Press. 
Hargreaves, A., \& Fink, D. (2006) Sustainable leadership. San Francisco: Jossey-Bass.

Haselden, K. G. (2004). Effects of co-teaching on the biology achievement of typical and at-risk students educated in secondary inclusion settings. Dissertation Abstracts International, 65(01). (ATT 3119816)

Havner, R. (2005). Special ed: The next big challenge. Mobile Register. Retrieved February 28, 2009, from http://www.al.com/news/mobileregister/index.ssf?/base/news

Hertz-Lazarowitz, R., \& Miller, N. (1992). The theoretical anatomy of group learning. Cambridge University Press.

Holloway, J. (2001). Inclusion and students with learning disabilities, Educational Leadership, 57(6), 86-88.

Huber, K. D., Rosenfeld, J. G., \& Fiorello, C. A. (2001). The differential impact of inclusion and inclusive practices on high, average and low achieving general education students. Psychology in the Schools, 38, 497-504.

Hull, J.R. (2005). General classroom and special education teachers' attitudes toward and perceptions of inclusion in relation to student outcomes. Pensacola, FL: University of West Florida.

Individuals With Disabilities Education Act Amendments of 1997 (IDEA '97), PL 10517, 105 U.S.C. 1400 et seq.

Individuals With Disabilities Education Improvement Act of 2004 (IDEA), PL 108446, 118 Stat. 2647 (2004). [Amending 20 U.S.C. 1400 et seq.].

Jacob, B. A. (2001). Getting tough? The impact of mandatory high school graduation exams on student outcomes. Educational Evaluation and Policy Analysis, 23(2): 99-122.

Johnson, Monica K., Robert Crosnoe, and Glen H. Elder, Jr. 2001. Students' attachment and academic engagement: The role of ethnicity. Sociology of Education 74, 31840.

Jones, K., Evans, C., Byrd, R., \& Campbell, K. (2000) Gender equity training and teaching behavior. Journal of Instructional Psychology, 27(3), 173-178.

Jones, M. G., Jones, B. D., and Hargrove, T. (2003). The unintended consequences of high-stakes testing. Lanham, MD: Rowman \& Littlefield.

Kalambouka, A., Farrell, P., Dyson, A., \& Kaplan, I. (2007). The impact of placing pupils with special educational needs in mainstream schools on the achievement of their peers. Educational Research, 49(4), 365-382. 
Kao, G., \& Thompson, J.S. (2003). Racial and ethnic stratification in educational achievement and attainment. Annual Review of Sociology, 29, 417-442.

Katsiyannis, A., Zhang, D., Ryan, J.B., \& Jones, J. (2007). High-stakes testing and students with disabilities; Challenges and promises. Journal of Disability Policy Studies, 18(3), 160-168.

Kavale, K. \& Forness, S. (2000). History, rhetoric and reality: Analysis of the inclusion debate. Remedial and Special Education, 21(5), 279-296.

Keefe, E. B., \& Moore, V. (2004). The challenge of co-teaching in inclusive classrooms at the high school level: What the teachers told us. American Secondary Education, 32(3), 77-88.

Kirkpatrick-Johnson, M., Crosnoe, R., \& Elder, G. (2001). Students' attachment and academic engagement: The role of race and ethnicity. Sociology of Education, 74(4), 318-341.

Kirsch, I., De Jong, J., LaFontaine, D., McQueen, J., Mendelovits, J., \& Monseur, C., (2002). Reading for change: Performance and engagement across countries, results from PISA 2000. Paris: Organization for Economic Co-operation and Development.

Knowles, R., \& Knowles, T. (2001). Accountability for what? Phi Delta Kappan, 82(5). 348-392.

Knudson, K. (2005). The effects of co-teaching in a secondary classroom on the academic achievement with mild to moderate disabilities. Dissertation Abstracts International, 43(06).

Kochhar, C.A., West, L.L. \& Taymans, J.M. (2000). Successful inclusion: Practical strategies for a shared responsibility. Upper Saddle River, NJ: Prentice Hall.

Kovacs, D. (2006). The inclusion experience of students with moderate and severe disabilities in general education classrooms. Oxford, OH: Miami University.

Lashway, L. (2001). The state of standards. Research Roundup, 17, 4.

LeCroy, C.W., \& Krysik, J. (2008). Predictors of academic achievement and school attachment among Hispanic adolescents. Children \& Schools, 30(4), 197-209.

Lee, J., \& Wong, K. (2004). The impact of accountability on racial and socioeconomic equity: Considering both school resources and achievement outcomes. American Educational Research Journal, 4(4) 797-832. 
Leithwood, K., \& Earl, L. (2000). Educational accountability effects: An international perspective. Peabody Journal of Education, 75(4), 1-18.

Lipsky, D. (2005). Are we there yet? Learning Disabilities Quarterly, 28, 156-158.

Losen, D., \& Orfield, G. (2002). Racial inequality in special education. Cambridge, MA: Harvard Education Press.

Louis, K.S., Febey, K., \& Schroeder, R. (2005). State-mandated accountability in high schools: Teachers' interpretations of a new era, Educational Evaluation and Policy Analysis, 27(20), 177-204.

Lowery, L. M. (2003). Instructional strategies and practices used to enhance student success in the high school Algebra I inclusive classroom. Blacksburg, VA: University Libraries, Virginia Polytechnic Institute and State University.

Lumsden, L. (1994). Student Motivation to Learn (ERIC Digest No. 92). ERIC Document Reproduction Service No. ED 370 200. Eugene, OR: ERIC Clearinghouse on Educational Management.

Marks, H. (2000). Student engagement in instructional activity: Patterns in the elementary, middle, and high school years. American Educational Research Journal, 37(1), 153-184.

Mastropieri, M. \& Scruggs, T. (2004) The inclusive classroom: Strategies for effective instruction. Upper Saddle River, N.J.: Pearson Merrill Prentice Hall

McDermott, P.A., Mordell, M., \& Stolzfus, J.C. (2001). The organization of student performance in American schools: Discipline, motivation, verbal learning, and non-verbal learning. Journal of Educational Psychology, 93, 65-76.

McDonnell, J., Thorson, N., Disher, S., Mathot-Buckner, C., Mendel, J., \& Ray, L. (2003). The achievement of students with developmental disabilities and their peers without disabilities in inclusive settings: An exploratory study. Education and Treatment of Children, 26(3), 224-236.

McLaughlin, M., Embler, S., Hernandez, G., Caron, E. (2005). No child left behind and students with disabilities in rural and small schools. Rural Special Education Quarterly, 24(1), 32-40.

McLaughlin, M. J., Fuchs, L., \& Hardman, M. (1999). Individual rights to education and students with disabilities: Some lessons from U.S. policy. In H. Daniels \& P. Garner (Eds.), Inclusive education: World yearbook of education 1999 (pp. 24$35)$. 
McLaughlin, M.J., Henderson, K., \& Rhim, I.M., (1998). Individual rights to education and students with disabilities: Some lessons from U.S. policy. Inclusive Education, 53, 24-35.

McLaughlin, M.J., \& Tilstone, C. (1999). Standards and curriculum: The core of educational reform, Ub M.J. McLaughlin \& M. Rouse (Eds.), Special education and school reform in the United States and Britain. London: Routedge, 38-65.

McNeil, L. (2000). Creating inequalities: Contradictions of reform. Phi Delta Kappan, 81(10), 728-734.

Merriam, S.B., (1998). Qualitative research and case study applications in education. San Francisco, CA: Jossey-Bass.

Mertens, D.M. \& McLaughlin, J.A. (2004). Research and evaluation methods in special education. Thousand Oaks, CA: Corwin Press.

Miami-Dade County Public Schools, (2008a). Retrieved June 17, 2008, from www.dadeschools.net

Miami-Dade County Public Schools. (2008b). Demographics report. Retrieved from http://dadeschools.net

Murawski, W., (2006). Introduction to special issue. Intervention in School and Clinic, 40(5), 284-291.

Murawski, W., \& Swanson, H. (2001). A meta-analysis of co-teaching research. Remedial \& Special Education, 22(5), 258-268.

Nagle, K \& Yunker, C (2006). Students with disabilities and Accountability Reform: Challenges issued at the state and local levels. Journal of Disabilities Policies Studies, 17(1), 28-39.

National Association of State Directors of Special Education. (2002, June). Implementing the No Child Left Behind act: What it means for IDEA, Alexandria, VA: Author.

National Center on Accessing the General Curriculum. (2002). Effective teaching practices and barriers limiting their use in accessing the curriculum: A review of recent literature. Washington, DC: Author.

National Center for Education Statistics. Retrieved June 17, 2009, from http://nces.ed.gov/

National Commission on Excellence in Education. (1983, April). A nation at risk. Author. Retrieved August 18, 2008, from http://www.ed.gov/pubs/NatAtRisk/risk.html 
National Research Council, (2000). How people learn: Brain, mind, experience, and school. Expanded edition. Committee on Developments in the Science of Learning, Committee on Learning Research and Educational Practice, Commission on Behavioral and Social Sciences and Education. Washington, DC: National Academy Press.

National Research Council, (2002). Minority students in special and gifted education. Committee on minority representation in special education, M.S. Donovan \& C.T. Cross, Eds; Division of Behavioral and Social Science and Education).Washington, DC: National Academy Press

Neill, M., Guisbond, L and Schaeffer, B., with Madison, J. \& Legeros, L. (2004). Failing our children: How "No Child Left Behind" undermines quality and equity in education and an accountability model that supports school improvement. Cambridge, MA: Fairtest.

Newman, I. (2000). A conceptualization of mixed methods: A need for inductive/deductive approach to conducting research. Paper presented at The Annual Meeting of the American Educational Research Association (New Orleans, LA, April 24-25, 2000).

Newman, I. \& Benz, C.R. (1998). Qualitative-quantitative research: Exploring the interactive continuum. Southern Illinois, Carbondale: University Press.

Newmann, Fred M. 1992. Student Engagement and Achievement in American Secondary Schools. New York: Teachers College Press.

Nichols, S. \& Berliner, D. C. (2005, March). The inevitable corruption of indicators and educators through high-stakes testing. EPSL-0503-101-EPRU. Retrieved August 23, 2008, from http://www.greatlakescenter.org/pdf/EPSL-0503-101-EPRU.pdf

Nichols, S., Glass, G., \& Berliner, D.C. (2006). High-stakes testing and student achievement: Does accountability pressure increase student learning? Educational Policy Analysis Archives, 14(1), 1-35.

No Child Left Behind Act of 2001. PL 107-220 (2001). Retrieved April 7, 2009, from http://www.gpo.gov

Nolet, V. \& McLaughlin, M. (2000). Accessing the general curriculum: Including students with disabilities in standards-based reform. Thousand Oaks, California: Corwin, Press, Inc.

Olivos, E. M. \& Quintana de Valladolid, C. E, (2005) Entre la Espada y la Pared: Critical Educators, Bilingual Education, and Education Reform: Journal of Latinos and Education, 4(4), 283-293. 
Onwuegbuzie, A.J., \& Leech, N. (2006). Linking research questions to mixed methods data analysis procedures. The Qualitatuve Report, 11(3), 474-498.

Orfield, G. \& Kornhaber, M.L. (2001) (Eds.). Raising standards or raising barriers? Inequality and high-stakes testing in public education. New York: The Century Foundation Press.

Patton, J.M. (1998). The disproportionate representation of African Americans in special education: Looking behind the curtain for understanding and solutions. The Journal of Special Education, 32(1), 25-31.

Paulen, P., Kallio, B., \& Stockard, R. (2001). The ethics of public school fiscal and academic accountability legislation: A multidimensional analysis. Journal of School Leadership,11(3 ), 162-180.

Pearpoint, J., Forest, M. \& Snow, J. (1992). The Inclusion Papers. Park, CA: Sage.

Pianta, R. C., La Paro, K. M., Payne, C., Cox, M. J., \& Bradley R. (2002). The relation of kindergarten classroom environment to teacher, family, and school characteristics and child outcomes. Elementary School Journal, 702(3), 225-238.

Rea, P., McLaughlin, V., \& Walther-Thomas, C. (2002). Outcomes for students with learning disabilities in inclusive and pullout programs. Exceptional Children, 68(2), 203-222.

Redmon, B.G. (2007). The impact of full inclusion on the academic achievement of students with disabilities in grades 3 to 6. Ed.D. dissertation, Tennessee State University, United States - Tennessee. Retrieved November 2, 2007, from ProQuest Digital Dissertation database. (Publication No. AAT 3267063).

Rimm-Kaufman, S. E., La Paro, K. M., Downer, J. T., Pianta, R. C. (2005). The contribution of classroom setting and quality of instruction to children $\mathrm{s}$ behavior in kindergarten classrooms. The Elementary School Journal, 105(4), 151-163.

Rotberg, I.C. (2004). Balancing change and tradition in global education reform. Lanham, MD: Rowman \& Littlefield.

Saint-Laurent, L., Dionne, J., Giasson, J., Royer, E., Simard, C. \& Pierard, B. (1998) Academic achievement effects of an in-class service model on students with and without disabilities. Exceptional Children, 64, 264-289.

Scheurich, J.J., Skrla, L., \& Johnson, J.F. (2000). Thinking carefully about equality and accountability. Phi Delta Kappan, 82, 293-300.

Sharpe, M., \& Hawes, M. (2003). Collaboration between general and special education: 
making it work. Special Education Programs, 2, 8-16.

Shernoff, D.J., Csikszentmihalyi, M., Schneider, B., \& Shernoff, E.S. (2003). Student engagement in high school classrooms from the perspecive of flow theory. School Psychology Quarterly, 18(2), 158-177.

Shernoff, D.J. \& Schmidt, J.A. (2007). Further evidence of an engagement-achievement paradox among U.S. high school students. J. Youth Adolescence, 37, 564-580.

Skrla, L., \& Scheurich, J. J., (2001). Displacing deficit thinking in school district leadership. Education and Urban Society, 33(3), 235-259.

Smith, T., Polloway, E., Patton, J., \& Dowdy, C. (1998). Educating young children with disabilities using responsible inclusion. Childhood Education, 74, 98-131.

State of Florida, (2000). Teaching Resources for Florida ESE. Retrieved September 19, 2009, from http://www.cpt.fsu.edu/ese/glossary.html\#accesspoints

Storm, W.M. (2006). Inclusion models in elementary physical education. Denvor, CO: Regis University.

Strieker, T. \& Logan, K. (2001). Everybody wins. The State Education Standard, 26-31.

Tashakkori, A. \& Creswell, J.W. (2007). Editorial: Exploring the Nature of Research Questions in Mixed Methods Research. Journal of Mixed Methods Research (1) 3-7.

Tashakkori, A. \& Newman, I. (2010, in press). Mixed methods: Integrating quantitative and qualitative approaches to research. In McGaw, B., Baker, E. \& Peterson, P. P. (Eds) International Encyclopedia of Education (3rd Edition). Oxford, UK: Elsevier.

Treder, D. W., Morse, W. C., \& Ferron, J. M. (2000). The relationship between teacher effectiveness and teacher attitudes toward issues related to inclusion. Teacher Education and Special Education, 23(3), 202-210.

Uekawa, K., Borman, K., \& Lee, R. (2007). Student Engagement in America's urban high school mathematics and science classrooms: Construction of a comprehensive model ad findings on race. Working paper, University of Chicago, University of Kyoto, and Japan Society for the Promotion of Science.

United States Census Bureau and the Federal Office of Management and Budget. Retrieved September 19, 2009, from http://www.en.wikipedia.org/wiki/Hispanics

U.S. Department of Education, (2003). Stronger accountability: Questions and answers 
on no child left behind. Retrieved March 4, 2009, from http://www.ed.gov/nclb/accountability/schools/accountability.html

U.S. Department of Education, Institute of Education Service. (2007) The nation's report card (2007) Mathematics. Retrieved November 12, 2008, from http://us.doe

U.S. Department of Education, Institute of Education Service. (2007) The nation's report card (2007) Reading. Retrieved November 12, 2008, from http://us.doe

Valenzuela, A. (2005) (Ed.). Leaving children behind: How "Texas-style" accountability fails Latino youth. Albany, NY: State University of New York Press.

Vasquez Heilig, J \& Darling-Hammond, L (2008). Accountability Texas-style: The progress and learning of urban minority students in a high-stakes testing context. Educational Evaluation and Policy Analysis. 30(2), 75-110.

Voelkl, K.E. (1997). Identification with school. American Journal of Education, 105, 294-318.

Voke, H. (2002, February). Motivating students to learn. ASCD Infobrief, 2(28). Retrieved August 19, 2009, from http://www.ascd.org/readingroom/infobrief/200202_issue28.html

Wallace, T., Anderson, A.R., Bartholomay, T. Hupp, S. (2002). An ecobehavioral examination of school classrooms that include students with disabilities. Exceptional Children, 68(3), 345-359.

Weiss, M.P. (2004). Co-teaching as science in the schoolhouse: More questions than answers. Journal of Learning Disabilities, 37(3), 218-223.

Wehmeyer, M.L., Lattin, D., \& Agran, M. (2001). Achieving access to the general curriculum for students with mental retardation. Education and Training in Mental Retardation and Developmental Disabilities, 36(4), 327-342.

Wellstone, P. (2000). High stakes test: A harsh agenda for America's children. Education Review, 29(7), 31-35.

Wood, J. M. (2000, March). The girls have it! [Electronic version]. Instructor, 109, 3135.

Yair, G. (2007). Not just location: LEAs and inequalities among schools. Journal of Educational Administration, 43(2/3), 295-316.

Yair, G. (2000). Educational battlefields in America: The tug-of-war over students' engagement with instruction. Sociology of Education, 73(4), 247-270. 
Yazzie-Mintz, E. (2007). Voices of students on engagement: A report on the 2006 High School Survey of Student Engagement. Retrieved September 28, 2008, from http://ceep.indiana.edu/hssse/pdf/HSSSE_2006_Report.pdf

Yin, R.K. (2003). Case study research, design, and methods, $3^{\text {rd }}$ edition. Newbury Park: Sage Publications.

Young, H.C. (2004). A survey of knowledge and implementation of best practices for inclusion by personnel prepared to teach students with severe disabilities. Thesis $(\mathrm{PhD})$. 
VITA

LISA A. BARROCAS

Florida International University

\section{EDUCATION}

Degree $\quad \underline{\text { Institution }} \quad$ Field $\quad \underline{\text { Dates }}$

M.S. Ed Florida State Mathematics Education June, 1998

University

B.S. Florida International

University

Special Education/

May, 1995

Emotionally Handicapped

\section{ACADEMIC EXPERIENCE}

Institution

Florida International

University

Florida International

University

Florida International

University

Place of Employment

Project QUEST

Instructor

Rank

Project IMPRESS

Coordinator
Field

Teaching and

Learning

Special Education

2008-2010

Special Education

Summer 2008

Dates

Miami-Dade County Public Exceptional Student Education

Schools, Miami, FL

Miami-Dade County Public

Schools, Miami, FL

Department Chairperson

Language Arts

Exceptional Student Education

Miami-Dade County Public Exceptional Student Education

Schools, Miami, FL

\section{PUBLICATIONS}

Nevin, A., Barrocas, L. et. al. (2006). Reviews of Single Subject Research Designs: Applications to Special Education and School Psychology. ERIC \# ED491545. 
Nevin, A., Barrocas, L. et. al. (2005). What Do Experts Say About Urban Special Education Issues? ERIC \# ED491410.

\section{PRESENTATIONS}

Florida Council for Exceptional Children (Sarasota, FL; October 2008). "Classroom Behavior Management: A Dozen Mistakes and What to do Instead."

Florida Council for Exceptional Children (Sarasota, FL; October 2008). "Special Education Students: A Self-Determination Advocacy Project."

Council for Exceptional Children (Ft. Lauderdale, FL; 2007). "Intellitools"

Council for Exceptional Children (Ft. Lauderdale, FL; 2007). "Timeliner"

Barrocas, L. (2007, December). “The Urban Inclusion Model”. Inclusion Expo. Miami, FL

Barrocas, L. (2007, May). “The Mentoring Process”. Presented at Project GATE End of Year Seminar

Teacher Education Division of the Council for Exceptional Children (San Diego, CA; November 2006). "Project Gate: A Collaborative University/District New ESE Teacher Mentoring Project."

Barrocas, L. (2005-2001) “Alternate Assessment Procedures" Presented at the Finishing Strong: A Closing of School Conference for New Teachers, Florida International University.

Barrocas, L. (2005-2004) “Efficient Lesson Plans and Gradebook.” Presented at District. 